\title{
Polysialic Acid Regulates Sympathetic Outflow by Facilitating Information Transfer within the Nucleus of the Solitary Tract
}

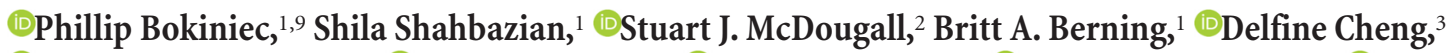 \\ -Ida J. Llewellyn-Smith, 4 (Deter G.R. Burke, ${ }^{5}{ }^{\oplus}$ Simon McMullan, ${ }^{1}$ @Martina Mühlenhoff, ${ }^{6}$ ○Herbert Hildebrandt, ${ }^{6}$ \\ Filip Braet, ${ }^{3,7} \circledast^{\circledR}$ Mark Connor, ${ }^{1}{ }^{\circledR N}$ Nicolle H. Packer, ${ }^{8}$ and ${ }^{\circledR A}$ Ann K. Goodchild ${ }^{1}$ \\ ${ }^{1}$ Department of Biomedical Sciences, Faculty of Medicine and Health Sciences, Macquarie University, Sydney, 2109 New South Wales, Australia, ${ }^{2}$ Florey \\ Institute of Neuroscience and Mental Health, University of Melbourne, Melbourne, 3010 Victoria, Australia, ${ }^{3}$ School of Medical Sciences, Discipline of \\ Anatomy and Histology, University of Sydney, Sydney, 2006 New South Wales, Australia, ${ }^{4}$ Cardiovascular Medicine and Human Physiology, Flinders \\ University, Adelaide, 5042 South Australia, Australia, ${ }^{5}$ Neuroscience Research Australia, Sydney, 2031 New South Wales, Australia, ${ }^{6}$ Institut für Zelluläre \\ Chemie, Medizinische Hochschule Hannover, Hannover 30625, Germany, ${ }^{7}$ Australian Centre for Microscopy and Microanalysis, University of Sydney, \\ Sydney, 2006 New South Wales, Australia, ${ }^{8}$ ARC Centre of Excellence in Nanoscale Biophotonics, Macquarie University, Sydney, 2109 New South Wales, \\ Australia, and ${ }^{9}$ Max Delbrück Center for Molecular Medicine, Robert-Roessle-Str. 10, Berlin, 13092, Germany
}

Expression of the large extracellular glycan, polysialic acid (polySia), is restricted in the adult, to brain regions exhibiting high levels of plasticity or remodeling, including the hippocampus, prefrontal cortex, and the nucleus of the solitary tract (NTS). The NTS, located in the dorsal brainstem, receives constant viscerosensory afferent traffic as well as input from central regions controlling sympathetic nerve activity, respiration, gastrointestinal functions, hormonal release, and behavior. Our aims were to determine the ultrastructural location of polySia in the NTS and the functional effects of enzymatic removal of polySia, both in vitro and in vivo. polySia immunoreactivity was found throughout the adult rat NTS. Electron microscopy demonstrated polySia at sites that influence neurotransmission: the extracellular space, fine astrocytic processes, and neuronal terminals. Removing polySia from the NTS had functional consequences. Whole-cell electrophysiological recordings revealed altered intrinsic membrane properties, enhancing voltage-gated $\mathrm{K}^{+}$currents and increasing intracellular $\mathrm{Ca}^{2+}$. Viscerosensory afferent processing was also disrupted, dampening low-frequency excitatory input and potentiating high-frequency sustained currents at second-order neurons. Removal of polySia in the NTS of anesthetized rats increased sympathetic nerve activity, whereas functionally related enzymes that do not alter polySia expression had little effect. These data indicate that polySia is required for the normal transmission of information through the NTS and that changes in its expression alter sympathetic outflow. polySia is abundant in multiple but discrete brain regions, including sensory nuclei, in both the adult rat and human, where it may regulate neuronal function by mechanisms identified here.

Key words: electron microscopy; nucleus of the solitary tract; patch clamp; polysialic acid; sympathetic nerve activity; viscerosensory afferents

Significance Statement

All cells are coated in glycans (sugars) existing predominantly as glycolipids, proteoglycans, or glycoproteins formed by the most complex form of posttranslational modification, glycosylation. How these glycans influence brain function is only now beginning to be elucidated. The adult nucleus of the solitary tract has abundant polysialic acid (polySia) and is a major site of integration, receiving viscerosensory information which controls critical homeostatic functions. Our data reveal that polySia is a determinant of neuronal behavior and excitatory transmission in the nucleus of the solitary tract, regulating sympathetic nerve activity. polySia is abundantly expressed at distinct brain sites in adult, including major sensory nuclei, suggesting that sensory transmission may also be influenced via mechanisms described here. These findings hint at the importance of elucidating how other glycans influence neural function. 


\section{Introduction}

The extracellular space is complex, filled with molecularly diverse matrix, a dynamic structure that influences neuronal function (Venstrom and Reichardt, 1993; Theodosis et al., 2008). This extracellular matrix is enriched in proteoglycans, as well as membrane bound glycoproteins and glycolipids commonly terminated by sialic acids, that form elaborate coats around all cells (Schnaar et al., 2014).

Polysialic acid (polySia) is a long, homopolymer composed of eight or more $\alpha 2,8$-linked sialic acids (Schauer, 2009; Chen and Varki, 2010). It is linked predominantly to the neural cell adhesion molecule (NCAM) and its expression is developmentally regulated (Bonfanti et al., 1992; Szele et al., 1994; Oltmann-Norden et al., 2008). In adult CNS, polySia expression is restricted to discrete regions that exhibit high levels of synaptic remodeling, including the hippocampus, cortex, and hypothalamus (Bonfanti et al., 1992; Rutishauser and Landmesser, 1996; Bonfanti, 2006; Hildebrandt and Dityatev, 2015). In these regions, polySia modulates synaptic plasticity and efficacy via a range of postulated mechanisms, including interactions with cell adhesion complexes, binding of neurotransmitter/neurotrophic substances, or via actions at glutamate receptors (Rutishauser and Landmesser, 1996; Rutishauser, 2008; Schnaar et al., 2014; Hildebrandt and Dityatev, 2015). In adults, polySia is also highly expressed in the nucleus of the solitary tract (NTS) (Bouzioukh et al., 2001a, b; Bonfanti, 2006). Despite such abundance, the precise location and function/s exerted by polySia in the NTS are unknown.

The NTS is a major integrative center receiving synaptic input from peripheral cardiovascular, respiratory, and gastrointestinal sensors as well as descending drive from higher brain centers, and is a critical relay of multiple homeostatic reflexes (Andresen and Paton, 2011; Pilowsky and Goodchild, 2002; Guyenet, 2006; Browning and Travagli, 2014). Glutamatergic viscerosensory afferents enter via the solitary tract and synapse with second-order NTS neurons (Talman et al., 1980; Appleyard et al., 2007; McDougall et al., 2009; Jin et al., 2010). Information is then relayed within the NTS or transmitted to more distal nuclei (Aicher et al., 1995; Hermes et al., 2006), driving a range of autonomic, hormonal, and behavioral responses. Plasticity occurs within the NTS, providing a beneficial adaptive mechanism acutely but chronically can be maladaptive, resulting in cardiovascular, respiratory, or gastrointestinal dysfunction (Kline, 2008; Browning and Travagli, 2010, 2014; Zoccal et al., 2014). Such plasticity is mediated by changes in presynaptic or postsynaptic excitability, via mechanisms, including quantal size, vesicle turnover, or release probability (Kline, 2008). The contribu-

Received Jan. 19, 2017; revised May 15, 2017; accepted May 25, 2017.

Author contributions: P.B., S.J.M., N.H.P., and A.K.G. designed research;P.B., S.S., B.A.B., D.C., I.J.L.-S., and A.K.G. performed research; M.M., H.H., F.B., and N.H.P. contributed unpublished reagents/analytic tools; P.B., B.A.B., I.J.L.-S., P.G.R.B., S.M., M.C., and A.K.G. analyzed data; P.B., S.J.M., B.A.B., I.J.L.-S., P.G.R.B., S.M., M.M., H.H., M.C., and A.K.G. wrote the paper.

P.B. is a scholar of the Australian Course in Advanced Neuroscience. This work was supported by the National Health and Medical Research Council of Australia APP1028183 and APP1030301, Australian Research Council DP120100920, and Hillcrest Foundation FR2014/0781. We thank Profs. John Bekkers and Javier Stern for helpful discussions regarding data collection and interpretation; Dr. Lama Bou-Farah for assisting in preliminary data collection; Prof. Rita Gerardy-Schahn for her valuable contribution; and Australian Microscopy and Microanalysis Research Facility (http://ammrforg.au/) node at the University of Sydney for facilities and scientific and technical assistance.

The authors declare no competing financial interests.

Correspondence should be addressed to Dr. Ann K. Goodchild, Department of Biomedical Sciences, Faculty of Medicine and Health Sciences, Macquarie University, Sydney, 2109 New South Wales, Australia. E-mail: ann.goodchild@mq.edu.au.

DOI:10.1523/JNEUROSCI.0200-17.2017

Copyright $\odot 2017$ the authors $\quad 0270-6474 / 17 / 376559-17 \$ 15.00 / 0$ tion of glycans to neurotransmission and/or plasticity in the NTS is unknown.

Only one group has investigated polySia in the NTS, demonstrating that high-frequency stimulation of the solitary tract reduced polySia expression (Bouzioukh et al., 2001a, b). Intriguingly, similar stimulation paradigms modify the effectiveness of excitatory and inhibitory synapses within the area (Miles, 1986; Glaum and Brooks, 1996; Zhou et al., 1997), resulting in increased sympathetic drive (Sun and Guyenet, 1987). Together, these data suggest that polySia in the NTS could modify neuronal function and the transfer of information to downstream networks, altering sympathetic nerve activity.

In exploring this hypothesis, we verified the distribution of polySia immunoreactivity in the adult rat NTS and described its ultrastructural location. Next, we determined the intrinsic neuronal properties and signaling mechanisms in the NTS altered by enzymatic removal of polySia, using whole-cell recordings in brain slice. Finally, we examined the consequences of this removal on sympathetic nerve activity in vivo. polySia was present at sites regulating information transfer: in fine astrocytic processes, the extracellular space, and axon terminals. We used multiple enzymes (neuraminidases) to desialylate glycans, including the polySia-specific enzyme, endo- $N$-acetyl-neuraminidase F (endoNF) (Stummeyer et al., 2005). Enzymatic removal of polySia within the NTS altered passive membrane properties, perturbed both high- and low-frequency viscerosensory afferent input, and increased sympathetic nerve activity. Our data indicate that, within the NTS, polySia expression is crucial for maintaining neuronal function and afferent transmission which, if altered, impacts signaling at downstream networks modifying sympathetic outflow.

\section{Materials and Methods}

Animal welfare and ethical approval

All experiments were conducted in accordance with the Australian Code of Practice for the Care and Use of Animals for Scientific Purposes and were performed with the approval of the Macquarie University Ethics Committee (Animal Research Authorities: 2012/015, 2014/019, 2014/ 041). Animals were housed under constant $12 \mathrm{~h}$ light/dark cycles and allowed standard rat chow ad libitum.

\section{Immunohistochemistry}

Immunohistochemical procedures were performed as previously described (Parker et al., 2013; Bou Farah et al., 2016). Male Sprague Dawley rats $(n=4)$ were anesthetized with sodium pentobarbital $(80 \mathrm{mg} / \mathrm{kg}$, i.p) and transcardially perfused with ice-cold DMEM followed by $4 \%$ PFA. Brains were removed and postfixed overnight in the same fixative. Coronal brainstem sections $(40 \mu \mathrm{m})$ were cut using a vibrating microtome (Leica VT 1200S). Free-floating sections were permeabilized in 50\% ethanol for $30 \mathrm{~min}$ at room temperature and washed in Tris-PBS (TPBS, $10 \mathrm{~mm}$ Tris, $0.9 \% \mathrm{NaCl}, 0.05 \%$ thimerosal in $10 \mathrm{~mm}$ phosphate buffer, $\mathrm{pH} 7.4)$. Sections were incubated in primary antibodies (diluted in 10\% normal horse serum in TPBS) against polySia (mouse Mab735, $0.1 \mu \mathrm{g} / \mathrm{ml}$, RRID: AB_2619682) or synaptophysin (rabbit anti-synaptophysin, 1:500, Synaptic Systems, \#101002, RRID: AB_2619681) for $48 \mathrm{~h}$ at $4^{\circ} \mathrm{C}$. Sections were washed and then incubated in fluorescent conjugated secondaries ( $\mathrm{Cy} 3$-conjugated donkey anti-mouse IgG, or 488-conjugated donkey anti-rabbit IgG, 1:250, Jackson ImmunoResearch Laboratories, \#715-165-151, RRID: AB_2315777, and \#711-545-152, RRID: AB_2313584, respectively) overnight at $4^{\circ} \mathrm{C}$. Sections were washed, mounted onto glass slides using Dako mounting medium, and visualized using a Zeiss upright microscope (Axio Imager Z.2). Images were acquired using ZEN 2012 imaging software (Zeiss). Highpower confocal images were visualized using a Leica confocal microscope (Leica TCS SP8) and acquired using Leica Application Software AF (Leica). All images were imported and analyzed using the ImageJ plugin Fiji (Schindelin et al., 2012). 


\section{Electron microscopy}

The method for electron microscopic immunocytochemistry was slightly modified (Llewellyn-Smith et al., 2005). Male Sprague Dawley rats ( $n=$ $4,10-12$ weeks of age) were anesthetized and perfused as described above with $4 \%$ formaldehyde and $0.3 \%$ glutaraldehyde (Electron Microscopy Sciences) in $0.1 \mathrm{~m}$ phosphate buffer, $\mathrm{pH}$ 7.4. Brains were removed and postfixed overnight in same fixative. Coronal sections of the medulla were cut into $50 \mu \mathrm{m}$ sections using a vibrating microtome (Leica VT 1200 S). Free floating sections were then permeabilized in 50\% ethanol for $3 \mathrm{~h}$ and washed briefly in phosphate buffer. Sections were blocked using $10 \%$ normal horse serum in TPBS for $30 \mathrm{~min}$ and subsequently incubated in primary antibody against polySia (mouse Mab735, $1 \mu \mathrm{g} / \mathrm{ml}$, RRID: AB_2619682) diluted in 10\% normal horse serum in TPBS for $7 \mathrm{~d}$. Sections were then incubated in biotinylated anti-mouse Ig (1:500, Jackson ImmunoResearch Laboratories, \#715-065-150, RRID: AB_2307438) for $4 \mathrm{~d}$ followed by exposure to ExtrAvidin-Peroxidase (1:1500, Sigma-Aldrich, \#E2886, RRID: AB_2620165) for a further $4 \mathrm{~d}$. All steps were performed at room temperature with sections washed in TPBS $(3 \times 30 \mathrm{~min})$ following each incubation. Immunoreactivity for polySia was detected with a nickelintensified 3,3'-DAB reaction using glucose oxidase. Sections were reacted for $30 \mathrm{~min}$ (or until strong signal was detected), and the reaction was halted with three washes in TPBS.

After the DAB reaction, sections were washed in $0.1 \mathrm{M}$ PBS, osmicated in $0.5 \%$ osmium tetroxide, stained en bloc with $1 \%$ aqueous uranyl acetate, and dehydrated through a graded series of acetone solutions. Sections were then infiltrated with 1:1 acetone:medium grade EPON resin and then in $100 \%$ resin overnight. Resin was periodically changed over $2 \mathrm{~d}$ before sections were flat embedded between glass slides and ACLAR plastic film and polymerized at $60^{\circ} \mathrm{C}$ for $48 \mathrm{~h}$. Regions of interest dissected using a scalpel blade and mounted onto flat blank blocks. Ultrathin sections $(60 \mathrm{~nm})$ were cut using a diamond knife and an ultramicrotome (Ultracut, Leica). Ultrathin sections were collected onto $200 \mu \mathrm{m}$ mesh copper grids. Selected grids were poststained with $2 \%$ uranyl acetate and Reynold's lead citrate and imaged using a transmission electron microscope (JEM-1400, JEOL). Electron micrographs were acquired using Digital Micrograph Software (Gatan), imported to and analyzed using the ImageJ plugin Fiji (Schindelin et al., 2012).

\section{In vitro electrophysiology data collection and analysis}

Brainstem slice preparation. Coronal and horizontal brainstem slices were collected from male Sprague Dawley rats as described previously (Andresen and Yang, 1990; Titz and Keller, 1997). Coronal slices: Rats (weight: 50-250 g; mean age: $\mathrm{P} 41 \pm 2$ ) were deeply anesthetized using isoflurane (5\% in $100 \% \mathrm{O}_{2}$, Cenvet) and once nociceptive reflexes (hindpaw pinch) were absent, quickly decapitated. The brainstem was rapidly removed and placed in ice-cold aCSF (in mM as follows: $125 \mathrm{NaCl}, 25 \mathrm{NaHCO}_{3}, 3$ $\mathrm{KCl}, 1.25 \mathrm{NaH}_{2} \mathrm{PO}_{4} \cdot \mathrm{H}_{2} \mathrm{O}, 25$ D-glucose, $2 \mathrm{CaCl}_{2}, 1 \mathrm{MgCl}_{2}$, equilibrated with $\left.95 \% \mathrm{O}_{2}-5 \% \mathrm{CO}_{2}\right)$. Coronal sections $(300 \mu \mathrm{m})$ were cut using a vibrating microtome (Leica VT 1200S). Slices of the medial NTS (bregma: -13.92 to $-13.56 \mathrm{~mm}$ ) (Paxinos and Watson, 2006) were collected and placed in warm $\left(34^{\circ} \mathrm{C}\right)$ aCSF and allowed to equilibrate for up to 60 min before recording. Horizontal slices: Rats (weight: 150-350 g; mean age: P56 \pm 4 ) were deeply anesthetized using isoflurane (Cenvet, $5 \%$ in $100 \% \mathrm{O}_{2}$ ) and once nociceptive reflexes (hindpaw pinch) were absent, quickly decapitated. The brainstem was rapidly removed and placed in ice-cold aCSF. The cerebellum was then removed and a wedge of the ventral surface removed so as to orientate the brainstem at an angle that allows a $250-\mu \mathrm{m}$-thick slice to contain both the solitary tract and the nucleus. Slices were cut using a vibrating microtome (Leica VT 1200S) and placed in warm $\left(34^{\circ} \mathrm{C}\right)$ aCSF. Slices were incubated for $60 \mathrm{~min}$ before recording. For "solitary tract evoked sustained current" protocol, the brainstem was initially incubated in ice-cold aCSF for $1 \mathrm{~min}$, then sliced and incubated in $\mathrm{Mg}^{2+}$-free aCSF for $60 \mathrm{~min}$ at $32^{\circ} \mathrm{C}$.

Recording parameters. Slices were placed in a custom-built chamber continuously bathed in aCSF warmed to $32^{\circ} \mathrm{C}$ (Temperature Controller TC-324B, Warner Instruments). Submerged sections were secured with a nylon harp and superfused at a rate of $2 \mathrm{ml} / \mathrm{min}$. All recordings were made from neurons within the intermediate NTS. Neurons were visualized using an Olympus microscope (BX51WI). Patch recording elec- trodes (3.5-5.5 M $\Omega$ ) were pulled using a P2000 laser pipette puller (Sutter Instruments) and filled with a potassium gluconate (K-Glu) internal solution consisting of (in mM) as follows: $10 \mathrm{NaCl}, 130 \mathrm{~K}-\mathrm{Glu}, 11 \mathrm{EGTA}$, 10 HEPES, $1 \mathrm{CaCl}_{2}, 2 \mathrm{MgCl}_{2}, 2 \mathrm{Na}_{2} \mathrm{ATP}, 0.2 \mathrm{Na}_{2} \mathrm{GTP}, 0.5 \%$ biocytin, $\mathrm{pH}$ 7.35-7.45, 290-295 mOsm. Recording electrodes were guided using a micromanipulator (Mp-225, Sutter Instruments).

Recordings were obtained using a Multiclamp 700B patch clamp amplifier (Molecular Devices), sampled at $20 \mathrm{kHz}$, and acquired using a 1401 CED computerized acquisition system (Cambridge Electronic Design), and analyzed offline using Spike2 software (Cambridge Electronic Design). The selection criteria for usable recordings were based on neuron stability, resting membrane potentials below $-45 \mathrm{mV}$ upon breaking in, series resistances $<25 \mathrm{~m} \Omega$, and input resistances $>200 \mathrm{~m} \Omega$. Series resistances were not compensated and liquid junction potentials not corrected. Data were not further analyzed if a $\geq 20 \%$ change in any of the parameters mentioned above was observed.

Steady-state outward currents. Coronal slices were initially incubated in aCSF, neuraminidase (Neu; $0.01,0.1,1 \mathrm{U} / \mathrm{ml})$, or endoNF $(0.1,1 \mu \mathrm{g} / \mathrm{ml})$ for $60 \mathrm{~min}$ at room temperature before recording. In whole-cell voltage clamp ( $-60 \mathrm{mV}$ clamped potential), membrane potentials were stepped in $10 \mathrm{mV}$ intervals to determine the currents generated ( -70 to $30 \mathrm{mV}, \Delta 10 \mathrm{mV}, 1000$ $\mathrm{ms}$ step). aCSF and endoNF activated steady-state outward currents tested in the following paradigms: (1) in the recording pipette, EGTA was substituted with the calcium-chelating agent BAPTA (10 mM, Sigma-Aldrich \#A4926); (2) the extracellular concentration of $\mathrm{CaCl}_{2}$ was lowered to $0.1 \mathrm{~mm}$; and (3) before and after superfusion of tetraethylammonium (TEA, 10 mM; SigmaAldrich \#T2265). Steady-state outward currents were measured as the last 50 $\mathrm{ms}$ of the current generated at each voltage step, normalized to baseline current. Two-way ANOVA with Bonferonni's correction was used for data analysis of steady-state outward currents. Unpaired Mann-Whitney test was used for comparison between enzyme treatments.

Current evoked action potential discharge and after hyperpolarization (AHP). Coronal slices were initially incubated in either aCSF or endoNF $(1 \mu \mathrm{g} / \mathrm{ml})$ for $60 \mathrm{~min}$ at room temperature before recording. In current clamp (at resting membrane potentials), neurons were injected with depolarizing currents ( $10-100 \mathrm{pA}, \Delta 10 \mathrm{pA}, 500 \mathrm{~ms}$ per step) to evoke action potential discharge. The number of action potentials generated was then compared between endoNF and control (aCSF) treatment. The AHP was measured at the peak change in membrane potential $(\mathrm{mV}) 5 \mathrm{~ms}$ after termination of $100 \mathrm{pA}$ current injection. AHP amplitude was then compared between endoNF and control (aCSF) treatment. Two-way ANOVA with Bonferonni correction was used for data analysis of action potential discharge. Unpaired $t$ test was used for comparison.

Stimulus-evoked action potential generation. In horizontal slices, evoked action potential generation was investigated in previously identified monosynaptically connected neurons (described below). Action potential generation was induced by solitary tract stimulation $(1 \mathrm{~Hz}, 20$ stimuli) recorded in current-clamp mode. The number of action potentials generated in response to 20 stimuli (following frequency) was then compared before and $30 \mathrm{~min}$ after endoNF $(1 \mu \mathrm{g} / \mathrm{ml})$ infusion in the same neuron. The latency of action potential generation was calculated as the time between the stimulus artifact and the onset of the action potential. Paired $t$ tests were used to compare responses.

Solitary tract evoked EPSCs and spontaneous EPSCs. A concentric bipolar stimulating electrode (200 $\mu \mathrm{m}$ outer tip diameter, Frederick Haer) was placed on the distal portion of the solitary tract rostral to the recording region. Using an Isolated Pulse stimulator (model 2100, A-M Systems), current shocks (100-800 $\mu \mathrm{A} ; \Delta 50 \mu \mathrm{A})$ were delivered to the solitary tract every $6 \mathrm{~s}$ (shock duration $0.5 \mu \mathrm{s}$ ) until a compound evoked EPSC (eEPSC) was observed. The latency of eEPSCs was calculated as the time between the stimulus artifact and onset of the first eEPSC. Synaptic jitter between responses was calculated as previously described (Doyle and Andresen, 2001) and a jitter (SD $<200 \mu$ s) was accepted to identify neurons connected monosynaptically. Only monosynaptically connected neurons were further analyzed. eEPSC amplitude and latency of solitary tract activation were subsequently recorded in the same neurons in the presence of aCSF and then endoNF ( $1 \mu \mathrm{g} / \mathrm{ml}, 30 \mathrm{~min})$. Spontaneous EPSCs (sEPSCs) were recorded in the absence of stimulation. sEPSC frequencies and amplitudes were compared in the presence of aCSF and then endoNF $(1 \mu \mathrm{g} / \mathrm{ml}$, 
$30 \mathrm{~min}$ ) in the same neuron. sEPSCs were characterized by having an amplitude $>10 \mathrm{pA}$ and interevent interval within $10 \mathrm{~ms}$. Paired $t$ tests were used to compare responses.

Solitary tract-evoked sustained current. In slices incubated and recorded in $\mathrm{Mg}^{2+}$-free aCSF, we first identified monosynaptically connected neurons as described above before delivering high-frequency current shocks $(50 \mathrm{~Hz}, 5-10$ stimuli) to the solitary tract to evoke NMDA-mediated sustained currents as previously described (Zhao et al., 2015). The sustained current was measured as the percentage change in current $100 \mathrm{~ms}$ following initiation of the first stimulus in the presence of $\mathrm{Mg}^{2+}$-free aCSF alone and then following endoNF ( $\left.1 \mu \mathrm{g} / \mathrm{ml}, 30 \mathrm{~min}\right)$ superfusion, in the same neuron. Paired $t$ tests were used to compare responses.

Miniature EPSCs (mEPSCs). mEPSCs were recorded in monosynaptically identified neurons, in the presence of the sodium channel blocker TTX (10 $\mu \mathrm{M}$, Jomar Bioscience, \#T550) and the GABA receptor antagonist gabazine (GBZ; $25 \mu \mathrm{M}$, Sigma-Aldrich, \#S106). Following recording of baseline mEPSCs (10 min, and until depolarizing steps injected in current clamp did not evoke action potentials), endoNF ( $1 \mu \mathrm{g} / \mathrm{ml})$ was superfused for $30 \mathrm{~min}$. The presence of glutamatergic mEPSCs was verified by infusion of the non-NMDA glutamate receptor antagonist CNQX $(10 \mu \mathrm{M}$, Sigma-Aldrich, \#C127) at the end of experimentation. mEPSC frequency was observed between single mEPSC events with amplitudes $>10 \mathrm{pA}$ and interevent intervals between $10 \mathrm{~ms}$, expressed in $10 \mathrm{~s}$ bins. Paired $t$ test was used for data analysis of all responses measured.

\section{Immunohistochemical characterization of recorded neurons}

Following electrophysiological experimentation, slices were incubated overnight in $4 \%$ PFA in PBS at $4^{\circ} \mathrm{C}$ followed by overnight incubation in cryoprotectant consisting of the following (in $\mathrm{mm}$ ): 0.5 polyvinylpyrrolidone, $76.7 \mathrm{Na}_{2} \mathrm{HPO}_{4}, 26.6 \mathrm{NaH}_{2} \mathrm{PO}_{4}, 876$ sucrose, 5 ethylene glycol. Slices were then processed for polySia immunoreactivity and recovery of recorded cells as described previously (Gogolla et al., 2006; Bou Farah et al., 2016). Briefly, free-floating sections were permeabilized using $0.5 \%$ Triton X-100 in $0.01 \mathrm{~m}$ PBS, overnight at $4^{\circ} \mathrm{C}$. Slices were then blocked in $5 \% \mathrm{BSA}$ in PBS for $4 \mathrm{~h}$ at room temperature. The antibody against polySia (mouse Mab735, $0.1 \mu \mathrm{g} / \mathrm{ml}$, RRID: AB_2619682) was added and slices incubated for a $4 \mathrm{~h}$ at room temperature. Slices were then incubated in secondary antibody (Cy3-conjugated donkey anti-mouse IgG, 1:250, Jackson ImmunoResearch Laboratories \#715-165-151, RRID: AB_2315777) and fluorophore-conjugated ExtrAvidin (ExtrAvidin-FITC, 1:500, SigmaAldrich \#E2761, RRID: AB_2492295) for detection of the biocytin-filled cells, overnight at $4^{\circ} \mathrm{C}$. Slices were washed, mounted onto glass slides using Dako mounting medium, and visualized using either a Zeiss upright microscope (Axio Imager Z.2), or Leica confocal microscope (Leica TCS SP8). Images were acquired and analyzed as described above.

\section{In vivo electrophysiology data collection and analysis}

Surgery and electrophysiological recordings. Male Sprague Dawley rats ( $n=26,10-12$ weeks of age) were anesthetized with urethane $(1.3 \mathrm{~g} / \mathrm{kg}$, i.p. $10 \%$ solution in saline, Sigma-Aldrich). Depth of anesthesia was assessed throughout each experiment by autonomic responses to hindpaw pinch. Core temperature was maintained between $36.5^{\circ} \mathrm{C}$ and $37^{\circ} \mathrm{C}$ by a homoeothermic heating blanket (Harvard Apparatus). The left femoral artery and vein were cannulated for measuring blood pressure and the administration of drugs and saline, respectively. The trachea was intubated to allow artificial oxygen-enriched ventilation. Rats were then paralyzed (pancuronium bromide, $0.8 \mathrm{mg} / \mathrm{kg}$, i.v.) and ventilated with end-tidal $\mathrm{CO}_{2}$ maintained between $3.5 \%$ and $4.5 \%$. Animals were placed in a stereotaxic frame and the left greater splanchnic sympathetic nerve isolated, cut and prepared for recording, using bipolar silver wire electrodes as described previously (Burke et al., 2008). Nerve recordings were amplified $(\times 10,000$; CWE), bandpass filtered $(0.1-3 \mathrm{kHz})$, sampled at $5 \mathrm{kHz}$ (CED Micro 1401, Cambridge Electronic Design) and recorded using Spike2 software (Cambridge Electronic Design).

NTS microinjection. The dorsal surface of the medulla was exposed by removal of the occipital plate. NTS injections sites were in accordance with the location of the intermediate NTS (Paxinos and Watson, 2006). Following a $30 \mathrm{~min}$ baseline period, injections were made with respect to the calamus scriptorius 0.4 and $0.8 \mathrm{~mm}$ rostral, 0.5 and $1.0 \mathrm{~mm}$ lateral, and 0.5 and $1.0 \mathrm{~mm}$ ventral to the dorsal surface, a total of 12 injections with a total injection volume of $800 \mathrm{nl}$. In some cases, vehicle control injections (12) were made before injection of enzymes. Following injection, responses were recorded for $60 \mathrm{~min}$ and at the end of experimentation rats were killed with an overdose of sodium pentobarbital $(80 \mathrm{mg} / \mathrm{kg}$, i.v.). Brains were removed and rapidly frozen to $-80^{\circ} \mathrm{C}$ before dissection of the region containing the NTS (see below). Immunoblot was used to determine the level of enzymatic digestion of polySia. Neurograms were amplified, rectified, and smoothed (integrated splanchnic sympathetic nerve activity [sSNA], $1 \mathrm{~s}$ time constant). Changes were expressed as a percentage of baseline activity (100\%). Time course analysis was obtained from data averaged over $5 \mathrm{~min}$ periods, from $5 \mathrm{~min}$ before microinjection to $60 \mathrm{~min}$ after completion of the microinjections. Data analysis was only performed after the injection period, as injection of any solution (including vehicle control) evoked fluctuations in sSNA. Peak responses were obtained at $60 \mathrm{~min}$ after the injection completion. Statistical analysis was performed using two-way ANOVA with Bonferonni correction. Comparison of enzymatic treatments was performed using the MannWhitney test.

\section{Western blot}

In vitro tissue collection. Coronal brain slices were collected as described above. Slices were then incubated in either aCSF, neuraminidase $(0.1 \mathrm{U} / \mathrm{ml}$, Sigma-Aldrich \#N2876) or endoNF ( $1 \mu \mathrm{g} / \mathrm{ml}$ ) (Stummeyer et al., 2005) for 0,45 , and $60 \mathrm{~min}$ at room temperature. Slices were then trimmed by removing the ventral half of the slice below the hypoglossal nucleus and the dorsal region was stored and frozen at $-80^{\circ} \mathrm{C}$.

In vivo tissue collection. To extract the brain region containing the NTS, brains were placed in an ice-cold brain matrix and a $2 \mathrm{~mm}$ rostrocaudal region of the brainstem was isolated as described previously ( $\mathrm{Da}-$ manhuri et al., 2012). The section was maintained frozen using dry ice and the region containing the NTS was hand cut using a scalpel blade (size 10).

Electrophoresis. Tissue was lysed using lysis buffer consisting of (in $\mathrm{mM}$ ) as follows: 320 sucrose, 2 EDTA, 4 HEPES, and $1 \%$ SDS. Protein was extracted by incubating tissue on ice for $10 \mathrm{~min}$, homogenizing with the FastPrep-24-homogenizer (MP Biomedicals) for $2 \times 40 \mathrm{~s}$ cycles, and then centrifuged for $30 \mathrm{~min}$ at $13,200 \mathrm{rpm}$ at $4^{\circ} \mathrm{C}$. Supernatants were kept and protein concentrations determined using the BCA protein assay kit (Thermo Fisher Scientific) according to the manufacturer's instructions. Equal amounts of protein $(20 \mu \mathrm{g})$ were loaded on a $7.5 \%$ polyacrylamide gel for electrophoresis. Proteins were then transferred onto a nitrocellulose membrane using the Trans-Blot Turbo System (Bio-Rad) and incubated in primary antibodies (diluted in 5\% skim milk in PBS) against either polySia (mouse Mab735, $1 \mu \mathrm{g} / \mathrm{ml}$, RRID: AB_2619682) or GAPDH (rabbit antiGAPDH, 1:5000, abcam, \#ab9485, RRID:AB_307275) overnight at $4^{\circ} \mathrm{C}$. HRP-secondary antibodies (goat anti-mouse IgG H and L, 1:10,000, and goat anti-rabbit IgG H and L, 1:10,000, R\&D Systems, \#HAF018, RRID: AB_573130, and \#HAF008, RRID:AB_357235, respectively) were incubated on the membrane at room temperature for $2 \mathrm{~h}$. Chemiluminescence detection was then performed using the Bio-Rad ECL kit and imaged using the Bio-Rad ChemiDoc system. All images were imported into ImageJ for densitometric analysis and expressed as a percentage change relative to protein loading control (GAPDH). One-way ANOVA with Bonferonni correction was used for comparison between treatments.

\section{Statistical analysis}

All values are expressed as mean \pm SEM. Paired or unpaired $t$ tests were used as indicated. One- or two-way ANOVA tests with Bonferroni post hoc tests were used as indicated. Mann-Whitney tests were used to determine whether different enzymes evoked different responses in sympathetic nerve activity. Statistically significant differences were considered at $p<0.05$. All statistical analysis was performed using GraphPad Prism 6.

\section{Drugs, enzymes, and reagents}

All drugs, enzymes and reagents, with the exception of endoNF (Stummeyer et al., 2005), or TTX (Jomar Biosciences) were purchased from Sigma-Aldrich. 

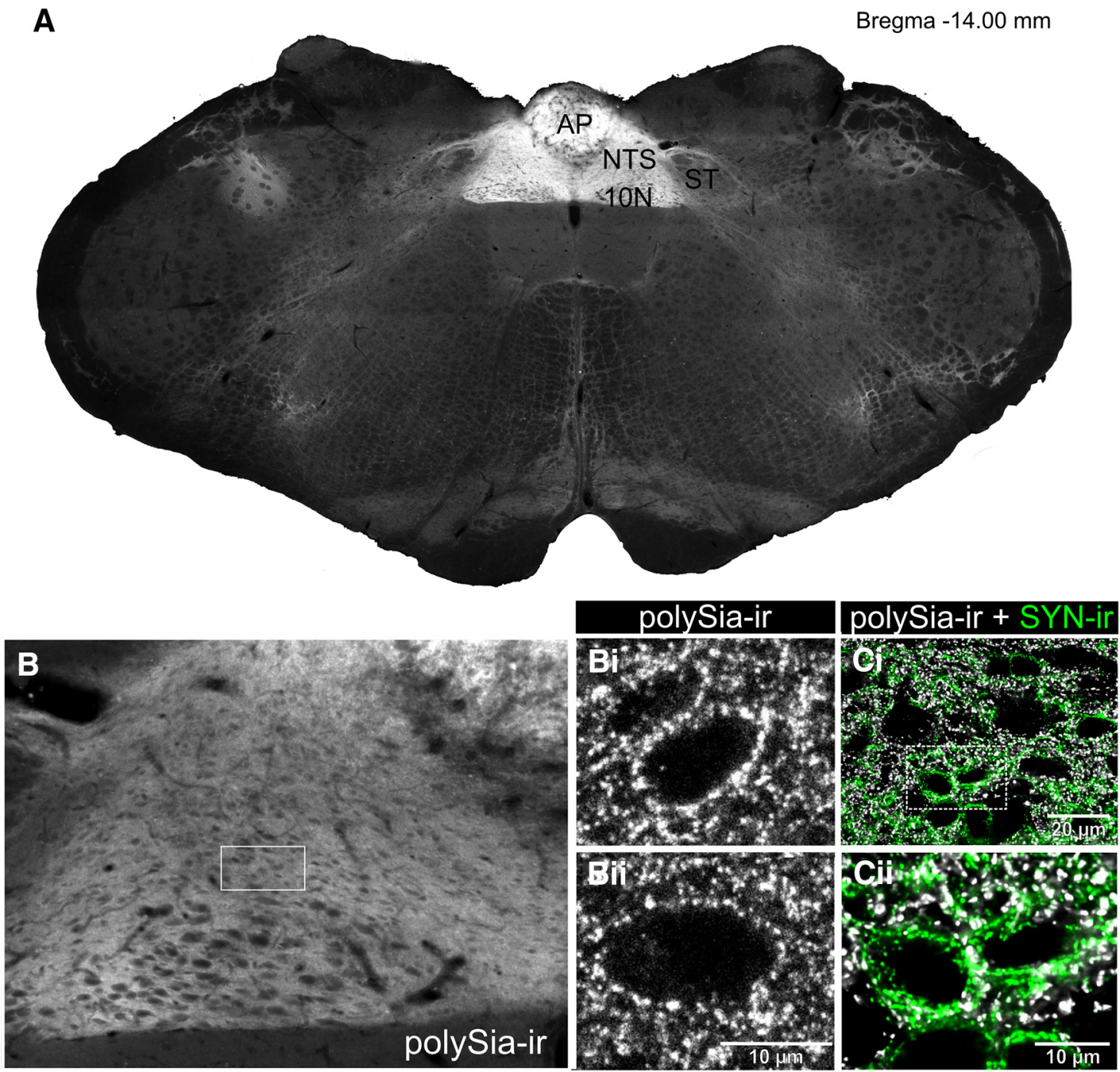

Figure 1. polySia immunoreactivity in the dorsal vagal complex. A, polySia immunoreactivity (ir) is abundant in the NTS, area postrema (AP), and dorsal motor nucleus of the vagus (10N) but not the solitary tract (ST) or surrounding regions (bregma level $-14.00 \mathrm{~mm}$ ). B, polySia-ir is seen throughout the NTS and dorsal motor nucleus of the vagus. $\boldsymbol{B i}$, Bii, polySia-ir puncta present throughout the neuropil and enveloping some unlabeled neurons. Ci, Cii, polySia-ir (white) closely apposes but rarely colocalizes with synaptophysin-ir (green) within the NTS.

\section{Results}

polySia is expressed abundantly within the neuropil of the NTS predominantly in fine astrocytic processes, the extracellular space, and apposing some synapses In the adult brain, polySia is expressed abundantly within NTS, the adjacent area postrema, and dorsal motor nucleus of the vagus (Bonfanti et al., 1992). We confirmed these observations using the polySia specific antibody Mab735 (Frosch et al., 1985), demonstrating that a high density of expression was restricted to this, the dorsal vagal complex (Fig. $1 A$ ). polySia immunoreactivity (ir) was densely distributed throughout the intermediate NTS (Fig. $1 B$ ), as individual puncta or as punctate rings surrounding unlabeled soma (Fig. 1Bi,Bii). Similar expression patterns were evident throughout the rostrocaudal extent of the nucleus (data not shown), suggesting potential influence over all functions controlled by the NTS: respiratory (caudal), cardiorespiratory (intermediate), gastrointestinal and gustatory (rostral), and all states influenced by the region: emotional, behavioral, and autonomic (Craig, 2003).

Electron microscopic immunohistochemistry revealed dense labeling of polysia in the space around neuronal cell bodies, fi- bers, and dendrites (Fig. 2A). polySia-ir does not colocalize with GFAP-labeled astrocytes in the NTS (Bouzioukh et al., 2001a). The ultrastructural location is therefore consistent with polySia present in or on the fine processes of astrocytes that lack GFAP and/or within the extracellular space or adjacent to plasma membranes (Fig. $2 A i$,Aii). The labeling pattern is consistent with the punctate rings of immunoreactivity that surround some neuronal cell bodies identified by light microscopy (Fig. 1Bi,Bii). polySia-ir was found on the rough endoplasmic reticulum and Golgi apparatus of some neuronal cell bodies (Fig. 2A) where it may be produced before being transported extracellularly to the cell surface (as described in the hypothalamus) (Theodosis et al., 1999). polySia-ir was also present adjacent to some synapses and in a subset of dendrites and axon terminals (Fig. 2B-E), consistent with the close association of polySia and synaptophysin revealed using immunofluorescence (Fig. 1Ci,Cii).

Enzymatic digestion of polySia enhances ionic currents of neurons in the NTS

To determine whether removal of sialic acids would alter the ionic conductance of NTS neurons, we first determined the time 


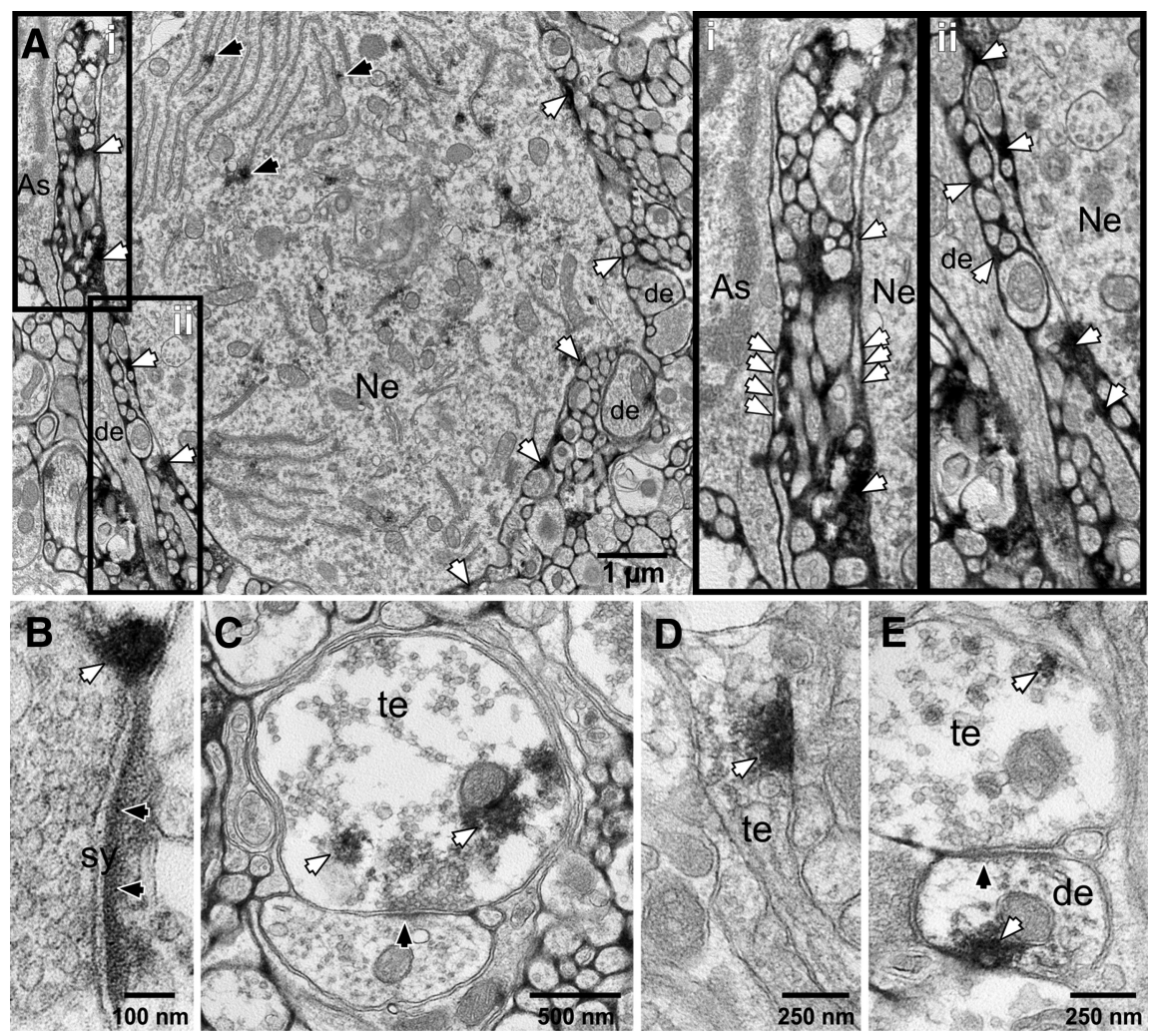

Figure 2. Ultrastructural location of polySia immunoreactivity. $\boldsymbol{A}$, Ultrastructural analysis shows polySia-ir (white arrows) surrounding neuronal soma (Ne), proximal dendrites (de), and fine neuronal processes consistent with expression in fine processes of astrocytes (As) (white arrows). polySia-ir is also found in the rough endoplasmic reticulum and Golgi apparatus of some neurons (black arrows). Ai, polySia-ir occurs along the exterior surface of the plasma membrane of some astrocytic (As) and neuronal (Ne) soma (white arrows) indicating its presence in the extracellular space. Aii, Dendrites (de) and axons are sheathed by polySia labeling. $\boldsymbol{B}$, polySia-ir (white arrows) was found adjacent to some synapses (sy) likely in astrocytic processes, as a tripartite synapse. $\boldsymbol{C}-\boldsymbol{E}$, polysia-ir is found within some dendrites (de) and axon terminals (te) of neurons. Black arrows indicate postsynaptic densities.

required for enzyme incubation of brain slices to remove sialic acids, measured by Western blot. Brain slices obtained and treated identically to those used for electrophysiological recordings were incubated in either aCSF $(n=3)$, aCSF containing the exosialidase neuraminidase from Clostridium perfringens (Neu; $0.1 \mathrm{U} / \mathrm{ml}, n=3$ ), which cleaves terminal $\alpha 2,3-, \alpha 2,6-$, and $\alpha 2,8-$ linked sialic acids (Taylor, 1996), or aCSF containing the endosialidase, endoNF ( $1 \mu \mathrm{g} / \mu \mathrm{l}, n=3)$, which is specific for polySia, as it cleaves $\alpha 2,8$ linkages within polymers with $>8$ sialic acid residues (Stummeyer et al., 2005; Taylor, 1996).

polySia-ir was stable during incubation in aCSF alone (Fig. $3 A$ ), and appeared to increase slightly during slice recovery, possibly due to increased synaptogenesis that occurs (Kirov et al., 1999). Densitometric evaluation, however, indicated no significant difference in expression during incubation in the absence of sialidases $\left(t_{(4)}=2.007, p=0.1152 ;\right.$ Fig. $\left.3 B\right)$. In contrast, one-way ANOVA revealed significant treatment effects when slices were incubated in exosialidases or endosialidases $\left(F_{(2,6)}=18.01, p=\right.$ 0.0029 ), with polySia-ir reducing significantly within $45 \mathrm{~min}$ (endoNF (green); $0.10 \pm 0.02$ a.u. vs $1.82 \pm 0.41$ a.u., $t_{(6)}=5.157$, $p=0.0042, n=3$ ) or $60 \mathrm{~min}$ (Neu (blue); $0.02 \pm 0.07$ a.u. vs $1.82 \pm 0.41$ a.u., $\left.t_{(6)}=5.237, p=0.0039, n=3\right)$.

We next investigated whether enzymatic digestion of polySia altered the current density profiles of NTS neurons. In whole-cell voltage clamp recordings of neurons from slices incubated in $\operatorname{aCSF}, \operatorname{Neu}(0.1,1$, and $10 \mathrm{U} / \mathrm{ml})$, or endoNF $(0.1$ and $1 \mu \mathrm{g} / \mathrm{ml})$ for
60 min, steady-state outward currents were evoked by $1000 \mathrm{~ms}, 10 \mathrm{mV}$ depolarizing voltage steps. Two-way ANOVA revealed significant enzymatic effect on responses when slices were incubated in $0.1 \mathrm{U} / \mathrm{ml} \mathrm{Neu}\left(F_{(1 / 47)}=21.54, p<\right.$ $0.0001)$, with increases in current density observed at $\mathrm{mV} \geq 0 \mathrm{mV}(0.1 \mathrm{U} / \mathrm{ml} \mathrm{Neu}$; $38.05 \pm 4.73 \mathrm{pA} / \mathrm{pF}$ vs aCSF, $19.93 \pm 1.70$ $\mathrm{pA} / \mathrm{pF}, t_{(517)}=4.290, p=0.0002, n=16$; Fig. $3 C, C i)$. Incubation in $0.01 \mathrm{U} / \mathrm{ml} \mathrm{Neu}$ $(n=11)$ had no effect $\left(F_{(1 / 42)}=0.03, p=\right.$ $0.858)$. Although a 10 -fold higher concentration $(1 \mathrm{U} / \mathrm{ml}, n=16)$ resulted in a significantly enhanced response compared with control $\left(F_{(1 / 47)}=25.75, p<0.0001\right)$, it did not evoke a greater response than slices incubated in $0.1 \mathrm{U} / \mathrm{ml}\left(F_{(1 / 30)}=\right.$ $1.65, p=0.208$ ) (Fig. 3Ci). Incubation in endoNF $(1 \mu \mathrm{g} / \mathrm{ml})$ also showed a treatment effect relative to control $\left(F_{(1 / 67)}=35.86, p<\right.$ $0.0001, n=36$; Fig. $3 D)$, and at $0 \mathrm{mV}$ evoked a $73 \%$ increase in current density $(35.84 \pm$ $2.45 \mathrm{pA} / \mathrm{pF}$ vs $20.66 \pm 1.10 \mathrm{pA} / \mathrm{pF}, t_{(737)}=$ $4.504, p<0.0001, n=36$ ), a profile matching that of Neu incubation $\left(F_{(50 / 500)}=\right.$ 287.24, $p<0.0001)$. A 10 -fold lower $(0.1$ $\mu \mathrm{g} / \mathrm{ml}, n=14)$ concentration of endoNF had no effect $\left(F_{(1 / 45)}=2.82, p=0.099, n=\right.$ 14; Fig. 3D).

The location of 21 recorded neurons (biocytin-filled; Fig. 3E, left) was plotted (recovery rate $=55 \%$ ), and all were found within the NTS (Fig. 3E). Consistent with our ultrastructural observations, analysis of a subset of recovered cells (from control slices not subjected to enzymatic treatment) consistently revealed punctate expression of polySia-ir enveloping both soma and proximal dendrites (Fig. $3 E$, left).

\section{Enzymatic digestion of polySia enhances $\mathrm{K}^{+}$-mediated} outward currents and increases intracellular $\mathrm{Ca}^{2+}$ release in NTS neurons

Delayed rectifier (IKDR) and large conductance calcium-activated (BK) potassium channels regulate the excitability of NTS neurons (Champagnat et al., 1986; Dekin and Getting, 1987; Dekin et al., 1987; Moak and Kunze, 1993; Andresen and Kunze, 1994). We therefore examined the effect of polySia removal on outward currents in the presence of TEA (10 mM), a blocker of IKDR. TEA application significantly reduced the amplitude of steady-state currents in both endoNF $\left(F_{(1 / 18)}=121.72, p<0.0001\right)$ treated and control slices $\left(F_{(1 / 10)}=24.69, p=0.0006\right)$, but no difference in amplitude was observed between groups $(2.78 \pm 1.53 \mathrm{pA} / \mathrm{pF}$ vs $4.67 \pm 2.10, F_{(1 / 14)}=1.15, p=0.30, n=10$; Fig. $4 A$, Ai), suggesting that polySia significantly contributes to IKDR channel function.

As TEA-sensitive channels include voltage-gated as well as BK channels (Coetzee et al., 1999), we investigated the effect of endoNF on BK channel activation, using the specific antagonist iberiotoxin (Ibtx, $50 \mathrm{~nm}$ ) (Pedarzani et al., 2000). In keeping with previous observations (Mayer et al., 2009), application of Ibtx in control slices significantly reduced steady-state outward currents $\left(F_{(1 / 12)}=3.60, p=0.08, n=7\right.$; Fig. $\left.4 B, B i\right)$. In contrast, Ibtx had 


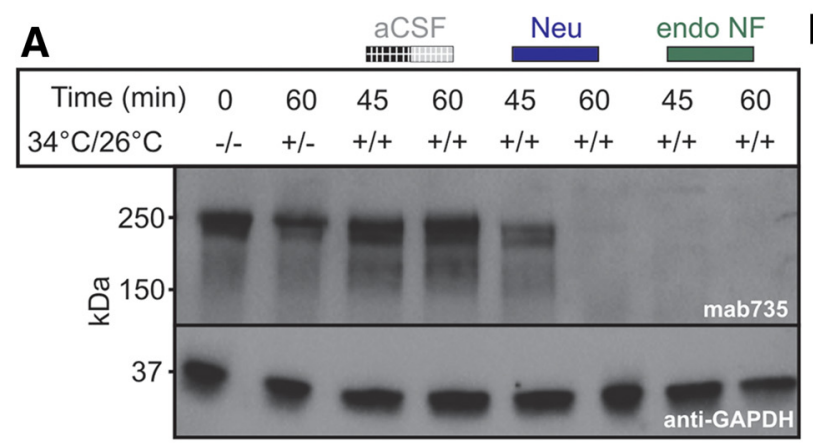

B

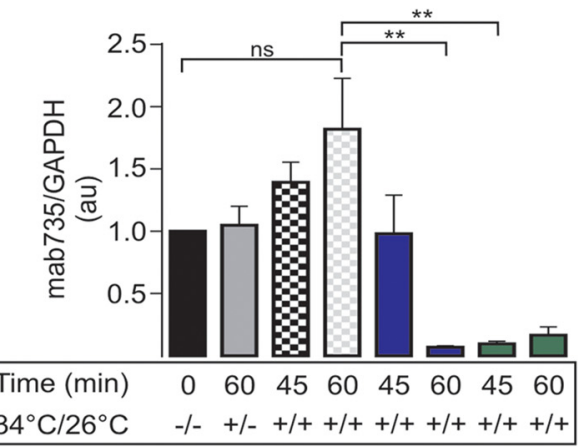

C
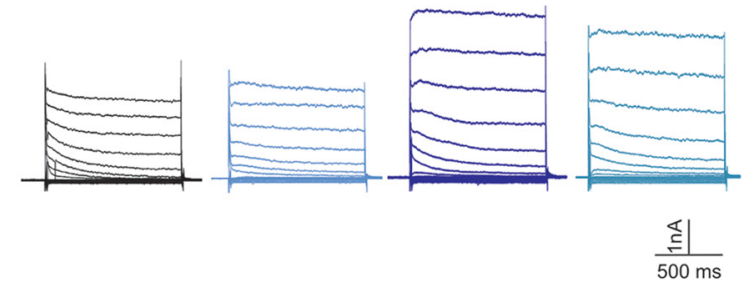

D

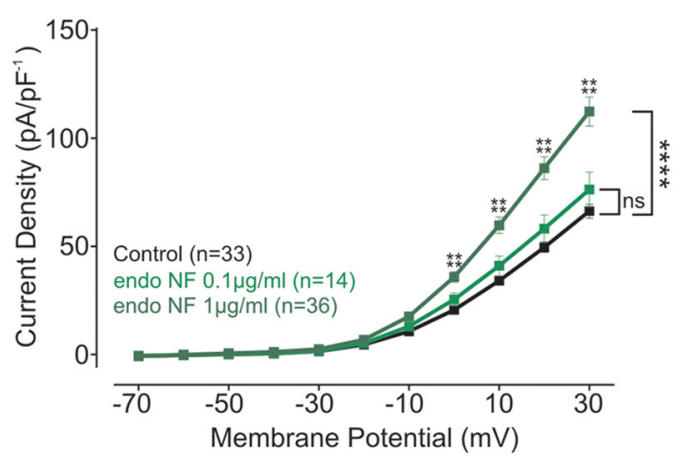

$\mathbf{C i}$

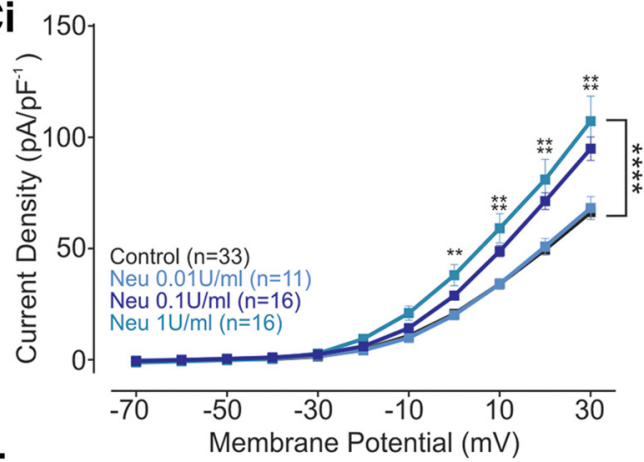

E

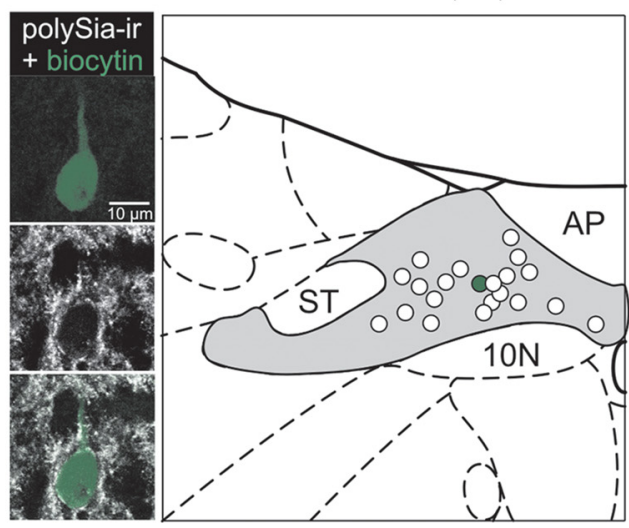

Figure 3. polySia removal enhances current voltage relationship within NTS neurons. $\boldsymbol{A}$, Representative Western blot using Mab735 to detect polySia during slice recovery, and following incubation in aCSF (gray/black box), Neu ( $0.1 \mathrm{U} / \mathrm{ml}$, blue box), or endoNF $(1 \mu \mathrm{g} / \mathrm{ml}$, green box). GAPDH was used as a loading control. $\boldsymbol{B}$, Comparison of the amount of protein detected using Mab735 during slice recovery (black and gray), and incubation in aCSF, Neu, or endoNF. polySia-ir was significantly reduced after 60 min incubation in Neu (blue box, $p=0.0039, n=3$ ) or 45 min incubation in endoNF (green box, $p=0.0042, n=3$ ). Data are normalized to GAPDH with the zero time point value set to 1 . Enzymatic removal of polySia in NTS brain slices increases steady-state outward currents. C, Typical current traces (depolarizing voltage step: $\Delta 10 \mathrm{mV}$ ) from NTS neurons incubated in aCSF (black), or Neu (0.01 U/ml, light blue, $0.1 \mathrm{U} / \mathrm{ml}$, dark blue, and $1 \mathrm{U} / \mathrm{ml}$, aqua, respectively). Ci, Grouped data reveal that Neu $(0.1$ and $1 \mathrm{U} / \mathrm{ml})$ significantly increased current density of neurons at depolarized potentials $\geq 0 \mathrm{mV}(p=0.0002, n=16$ and $n=11$, respectively). $\boldsymbol{D}$, Grouped data show that incubation in endoNF at $1 \mu \mathrm{g} / \mathrm{ml}$ (dark green), but not $0.1 \mu \mathrm{g} / \mathrm{ml}$ (light green), significantly increased current density of neurons at depolarized potentials $\geq 0 \mathrm{mV}$ ( $p<0.0001, n=36)$. Data are mean \pm SEM. E, Recovered cell (green) within theNTS surrounded by polySia-ir puncta (white) coating the soma and proximal dendrite. The recovered cell was recorded while superfused with aCSF (control). Schematic coronal section showing distribution of recorded neurons in the NTS recovered following incubation in aCSF or endoNF. ${ }^{* *} p<0.01$; ${ }^{* * *} p<0.0001 ; \mathrm{ns}, p<0.05$.

no effect in endoNF-treated slices $\left(F_{(1 / 6)}=0.30, p=0.60, n=4\right.$; Fig. $4 \mathrm{~B}, \mathrm{Bi})$, suggesting that BK channel function was perturbed by polySia removal. Current injections did not alter the number of action potentials generated $\left(F_{(1 / 35)}=0.21, p=0.65\right.$; Fig. $5 A, A i)$ or the amplitude of the $\operatorname{AHP}\left(t_{(18)}=0.133, p=0.90\right.$; Fig. $5 B$ ) in keeping with a reduced ability of Ibtx to close BK channels following polySia digestion (Yang et al., 2015). These data indicate that IKDR and BK channel function are both altered by the removal of polySia.

The effect of endoNF on steady-state currents was voltagedependent and significantly enhanced at the equilibrium potential for $\mathrm{Ca}^{2+}$ (9 $\mathrm{mV}$ under the recording conditions), so we examined whether polySia altered $\mathrm{Ca}^{2+}$ currents. We first omitted $\mathrm{Ca}^{2+}$ from the external solution preventing $\mathrm{Ca}^{2+}$ influx during depolarization. Under these conditions, enzymatic digestion of polySia still enhanced steady-state currents $\left(F_{(1 / 28)}=5.40, p=\right.$ 0.027, $n=15$; Fig. 4C) that were indistinguishable from those evoked by endoNF under normal levels of external $\mathrm{Ca}^{2+}$ $\left(F_{(1,49)}=0.002, p=0.96\right)$. Next, we substituted EGTA within the recording pipette for the fast $\mathrm{Ca}^{2+}$ chelator BAPTA $(10 \mathrm{~mm})$ to assess the contribution made by internal $\mathrm{Ca}^{2+}$ stores. We found that BAPTA eliminated the enhanced steady-state outward currents normally observed following polySia digestion $\left(F_{(1 / 28)}=\right.$ $0.15, p=0.70, n=13$; Fig. $4 D$ ).

Together, these data indicate that removal of polySia from NTS neurons facilitated currents generated through $\mathrm{K}^{+}$channels, reduced inactivation of BK channels, and increased $\mathrm{Ca}^{2+}$ via release from intracellular stores. 

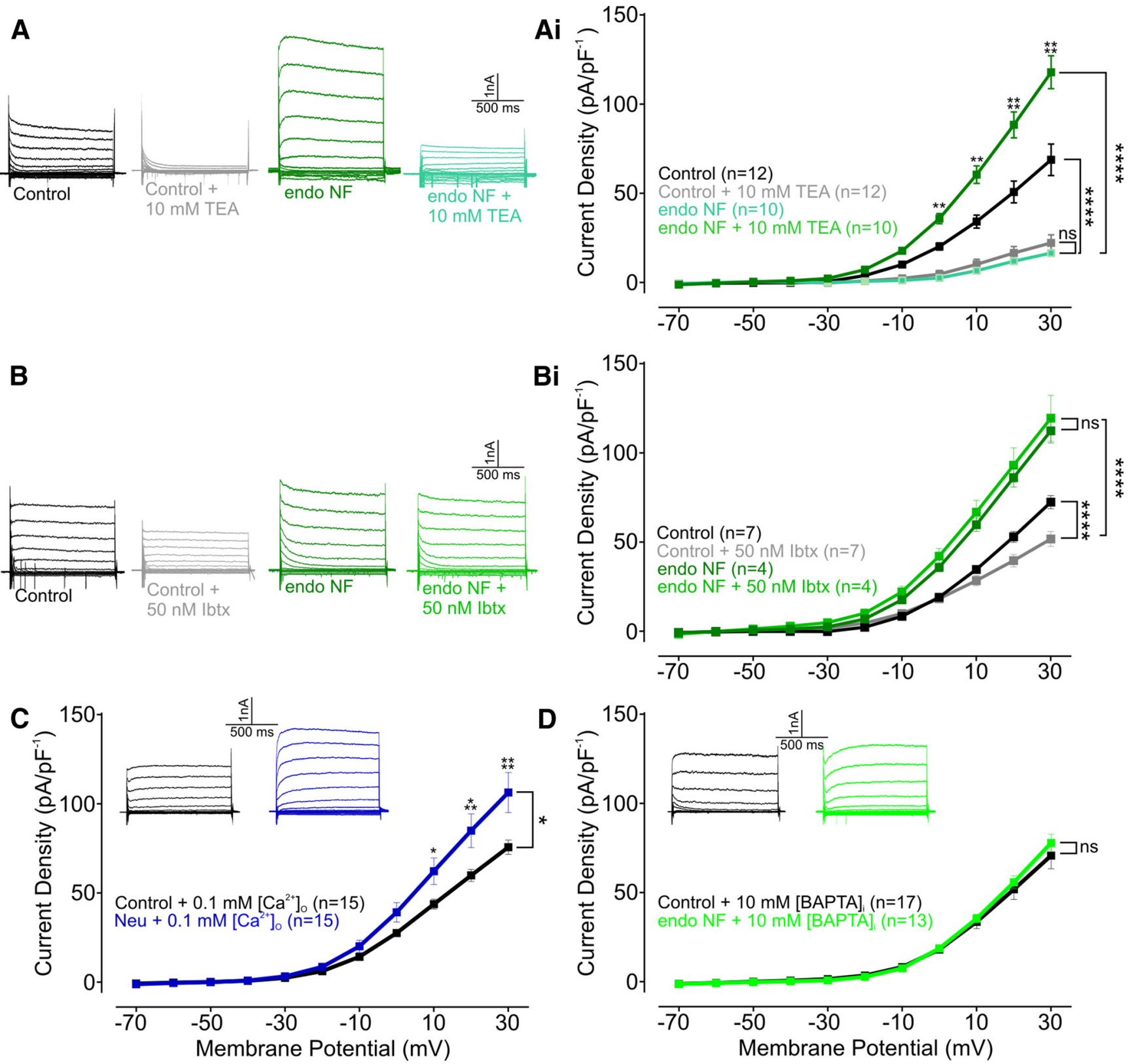

Figure 4. polySia removal enhances $\mathrm{K}^{+}$currents, and intracellular $\mathrm{Ca}^{2+}$ in NTS neurons. $A$, Typical current traces (depolarizing voltage step: $\Delta 10 \mathrm{mV}$ ) of NTS neurons recorded following slice incubation in either aCSF (black), aCSF containing TEA (10 mm, gray), endoNF (1 $\mu \mathrm{g} / \mathrm{ml}$, green), or endoNF containing TEA (10 mm, light green). Ai, Grouped data reveal that TEA treatment reduced currents generated in aCSF $(p=0.0006, n=10)$ and endoNF-treated slices $(p<0.0001, n=12$ and $n=10$, respectively) with no difference between groups $(p=0.30, n=10) . \boldsymbol{B}$, Typical current traces (depolarizing voltage step: $\Delta 10 \mathrm{mV}$ ) of NTS neurons recorded following slice incubation in either aCSF (black), aCSF containing lbtx (50 nm, light gray), endoNF (green), or endoNF containing Ibtx ( $50 \mathrm{~nm}$, light green). Bi, Grouped data reveal that Ibtx reduced currents generated in aCSF $(p=0.08, n=7)$ but did not alter currents generated in endoNF-treated slices $(p=0.60$, $n=4)$. Endo NF + Ibtx currents generated were significantly different to aCSF + Ibtx currents ( $p=0.0002)$. C, Typical current traces (depolarizing voltage step: $\Delta 10 \mathrm{mV}$ ) of NTS neurons recorded following slice incubation in either aCSF or Neu with reduced extracellular $\mathrm{Ca}^{2+}$ concentration $\left(\left[\mathrm{Ca}^{2+}\right]_{0}, 0.1 \mathrm{~mm}\right.$, black and blue, respectively). Grouped data show that increased currents were generated by Neu when $\left[\mathrm{Ca}^{2+}\right]_{0}$ was reduced $(p=0.027, n=15)$. D, Typical current traces (depolarizing voltage step: $\Delta 10 \mathrm{mV}$ ) of NTS neurons recorded following slice incubation in either aCSF or endoNF with EGTA substituted for BAPTA in the recording pipette $(10 \mathrm{~mm}$, black and green, respectively). Grouped data reveal no change in currents generated between aCSF and endoNF $(p=0.70, n=13)$. Hyperpolarizing spikes were truncated to aid visual representation. Data are mean \pm SEM. ${ }^{*} p<0.05 ;{ }^{* *} p<0.01 ;{ }^{* * *} p<0.001 ;{ }^{* * * *} p<0.0001 ; n s, p>0.05$.

polySia contributes to glutamatergic viscerosensory afferent transmission in NTS

We next investigated whether polySia removal affected viscerosensory afferent transmission. In second-order NTS neurons, identified as receiving monosynaptic input from viscerosensory afferents, enzymatic cleavage of polySia reduced the fidelity of action potentials generated by afferent activation (Fig. 6A). Consistent with previous observations (Bailey et al., 2007), consecutive, $1 \mathrm{~Hz}$ minimal amplitude electric stimulation generated action potentials with $86.0 \pm 5.1 \%$ fidelity under control conditions previous shown to be mediated by AMPA receptors. In the same neurons, following polySia digestion with endoNF, fidelity decreased to $31.0 \pm 3.3 \%\left(t_{(4)}=9.297, p=0.0007, n=5\right.$; Fig. $6 \mathrm{Ai}$ ). Furthermore, polySia digestion increased the latency of action potential propagation following stimulation of viscerosensory afferents (Fig. $6 B)$ by $41.7 \%(8.79 \pm 1.56 \mathrm{~ms}$ vs $5.12 \pm 0.61$ $\mathrm{ms}, t_{(4)}=3.96, p=0.021, n=5$; Fig. $\left.6 \mathrm{Bi}\right)$. No significant differences were observed in basal action potential parameters, includ- 
A

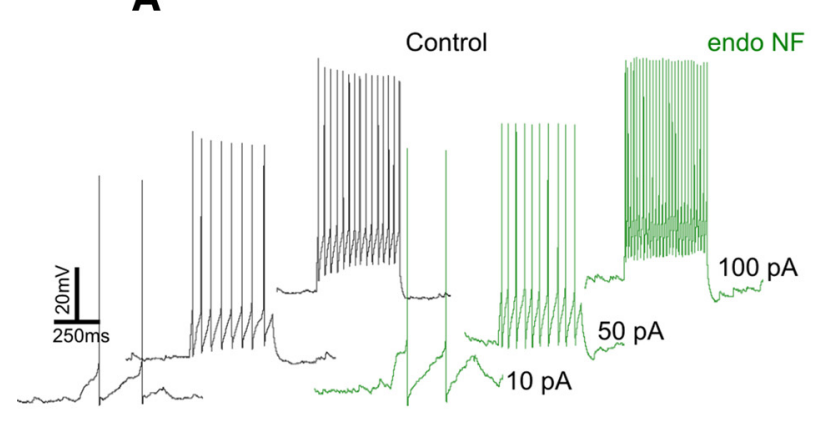

Ai 40

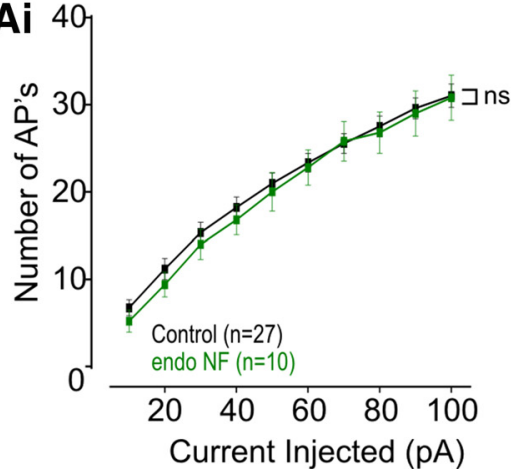

B

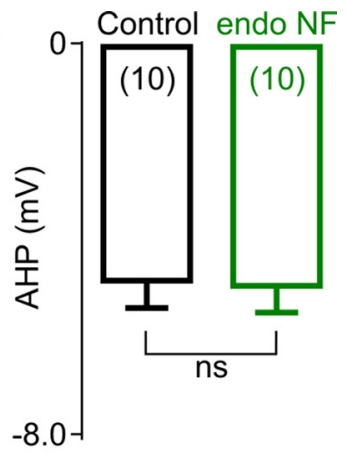

Figure 5. Action potential discharge and AHP following current injection are not altered after enzymatic digestion of polySia. A, Typical current traces of action potentials generated by current injections (10,50, and $100 \mathrm{pA}$ ) in cells incubated in aCSF (control, black) or endoNF (green). Ai, Grouped data show that enzymatic digestion of polySia did not alter action potential discharge to current injections $(p=0.65, n=10)$. $\boldsymbol{B}$, Grouped data revealed no change in AHP amplitude following enzymatic cleavage of polySia $(p=0.90, n=10)$. Data are mean \pm SEM.
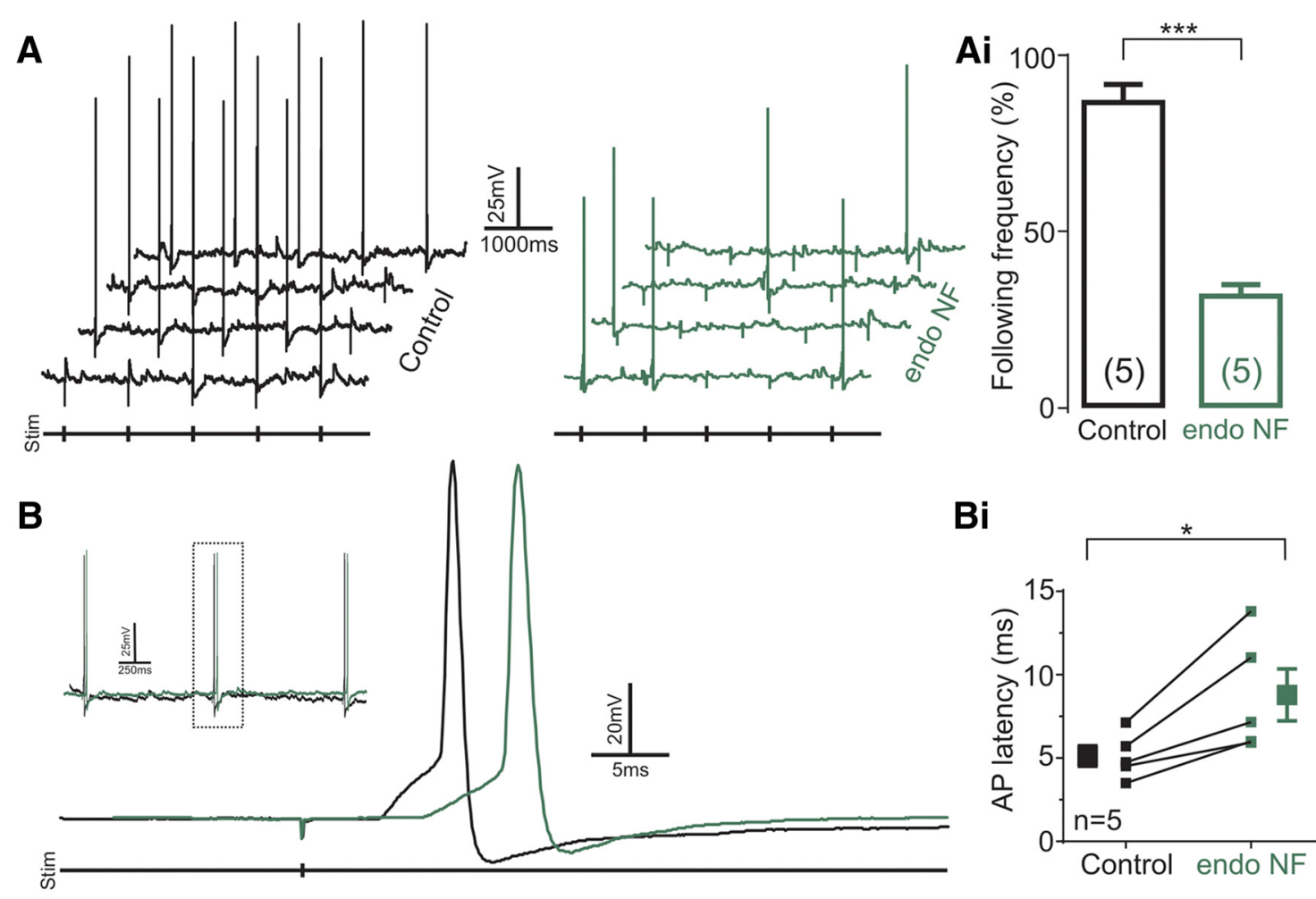

Figure 6. polySia removal reduces viscerosensory afferent signal transmission in the NTS. A, Typical voltage trace of monosynaptically connected NTS neurons with action potentials generated following viscerosensory afferent stimulation ( $1 \mathrm{~Hz}$ ) before (black) and $60 \mathrm{~min}$ after (green) endoNF incubation. Ai, Grouped data show that endoNF decreased the following frequency in response to viscerosensory afferent stimulation from $86 \%$ to $31 \%(p=0.0007, n=5)$. $\boldsymbol{B}$. Typical voltage trace of monosynaptically connected NTS neuron showing action potential latency following viscerosensory afferent stimulation ( $1 \mathrm{~Hz}$ ) before (black) and after (green) endoNF incubation. Inset, aCSF (black) and endoNF (green) traces overlaid and aligned to the stimulus artifact. $\boldsymbol{B} \boldsymbol{B}$, Grouped data reveal that endoNF treatment increased the latency in response to viscerosensory afferent stimulation $(1 \mathrm{~Hz})$ by $71.6 \%(p=0.021, n=5)$. Data are mean $\pm S$ SEM. ${ }^{*} p<0.05$; ${ }^{* * *} p<0.01$.

ing membrane potential $(-51.60 \pm 2.14 \mathrm{mV}$ vs $-49.20 \pm 1.72$ $\left.\mathrm{mV}, t_{(4)}=2.59, p=0.061, n=5\right)$, action potential amplitude $\left(92.03 \pm 7.27 \mathrm{mV}\right.$ vs $93.18 \pm 3.50 \mathrm{mV}, t_{(4)}=0.27, p=0.80, n=$ $5)$, half-width ( $1.54 \pm 0.30 \mathrm{~ms}$ vs $1.10 \pm 0.16 \mathrm{~ms}, t_{(4)}=2.40, p=$ $0.074, n=5)$, rise time $(90 \%-10 \% ; 1.72 \pm 0.50 \mathrm{~ms}$ vs $1.68 \pm 0.38$ $\left.\mathrm{ms}, t_{(4)}=0.13, p=0.91, n=5\right)$, spike threshold $(-39.80 \pm 2.22$ vs $-33.31 \pm 0.87, t_{(4)}=2.58, p=0.061, n=5$ ), or decay time $\left(\mathrm{T}_{90 \%-10 \%} ; 1.96 \pm 0.21 \mathrm{~ms}\right.$ vs $1.64 \pm 0.17 \mathrm{~ms}, t_{(4)}=1.40, p=0.23$, $n=5)$. These data suggest that polySia expression enables monosynaptic transmission from viscerosensory afferents onto NTS neurons.

As the fidelity of action potential transmission is perturbed following polySia removal in the NTS, we investigated whether excitatory drive from viscerosensory afferents would similarly decline. As described previously (Doyle and Andresen, 2001), suprathreshold electrical stimuli applied to viscerosensory afferents evoke large monosynaptic EPSCs (eEPSCs), identified by low failure rates and jitters ( $<200 \mu \mathrm{s} ; 140.60 \pm 13.63 \mu \mathrm{s}, n=12)$. Consistent with effects on action potential probability and latency, enzymatic digestion of polySia increased eEPSC latency by $31.1 \%\left(4.97 \pm 0.44 \mathrm{~ms}\right.$ vs $3.79 \pm 0.38 \mathrm{~ms}, t_{(9)}=3.51, p=0.0066$, $n=10$; Fig. $7 A, A i)$, and decreased the amplitude of eEPSCs recorded in voltage-clamp mode by $54.4 \%$ (198.60 $\pm 31.14 \mathrm{pA}$ vs $412.20 \pm 59.93 \mathrm{pA} t_{(9)}=5.527, p=0.0004, n=10$; Fig. 7 A, Aii). In contrast, jitter $\left(159.90 \pm 7.30 \mu \mathrm{s}\right.$ vs $134.60 \pm 10.06 \mu \mathrm{s}, t_{(9)}=$ 2.242, $p=0.0517, n=10$ ), paired-pulse ratio (EPSC2/EPSC1; 
A

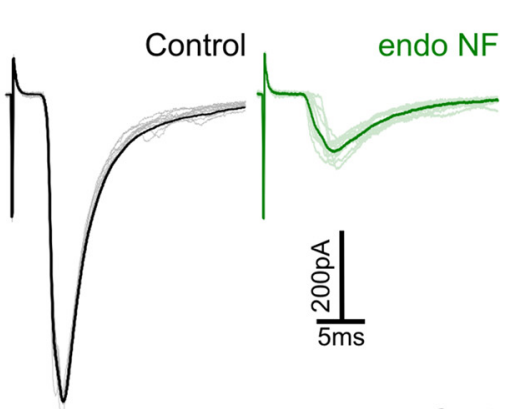

B
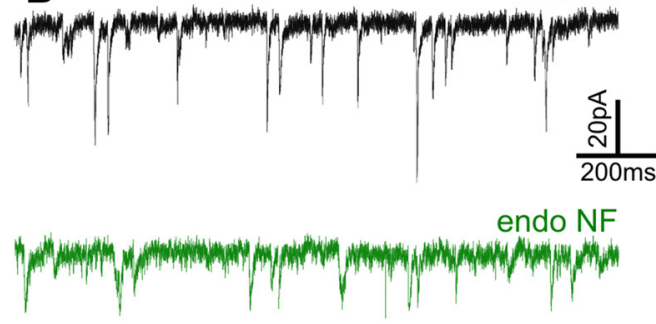

C

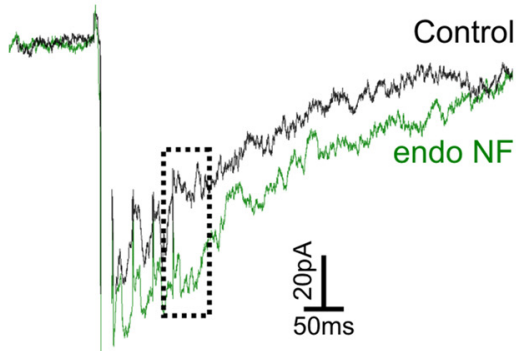

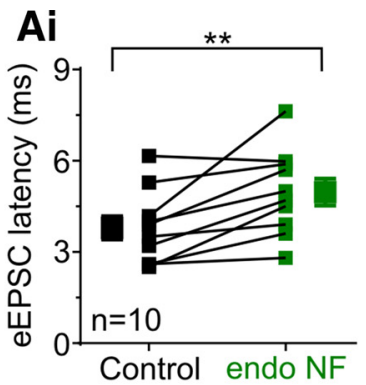
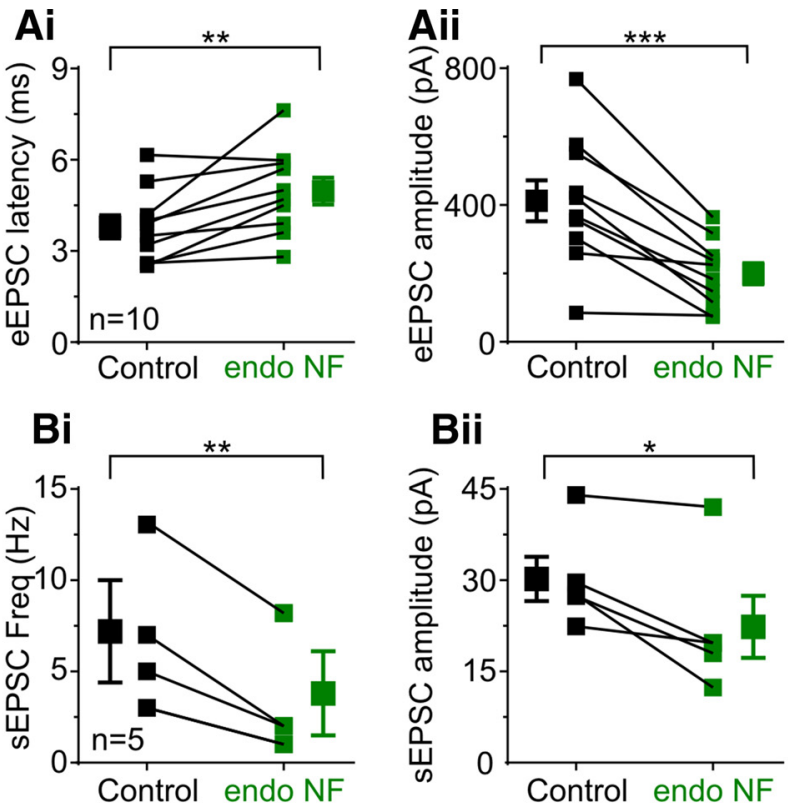

Ci

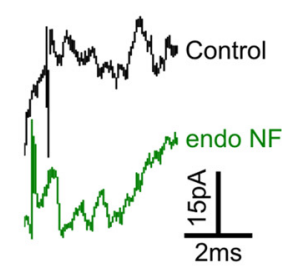

Bii

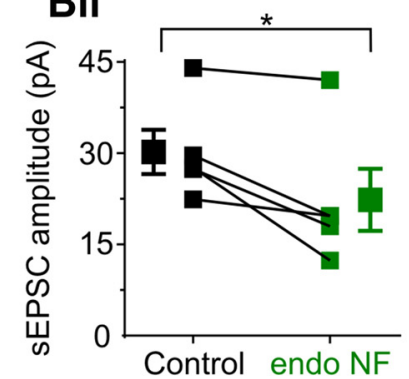

Cii

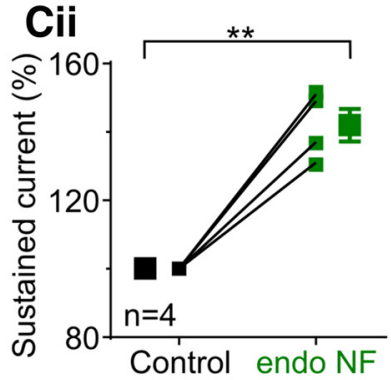

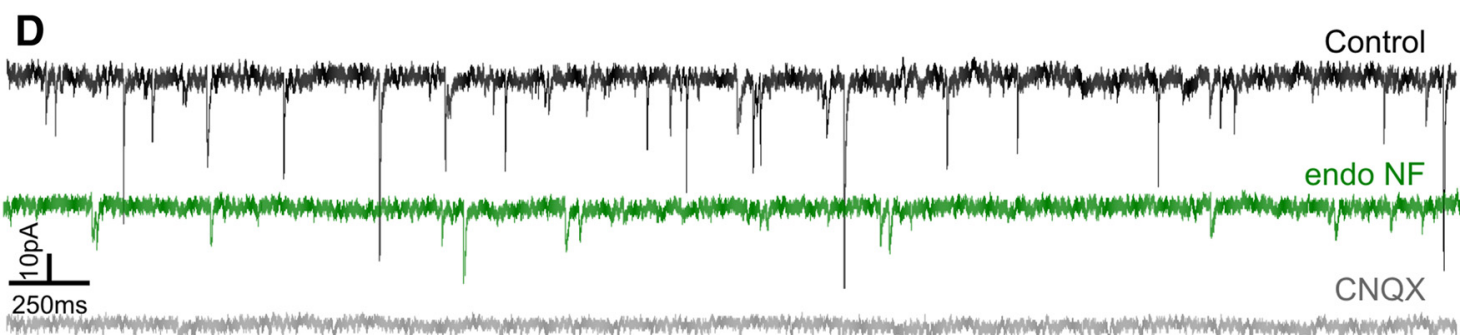

Di

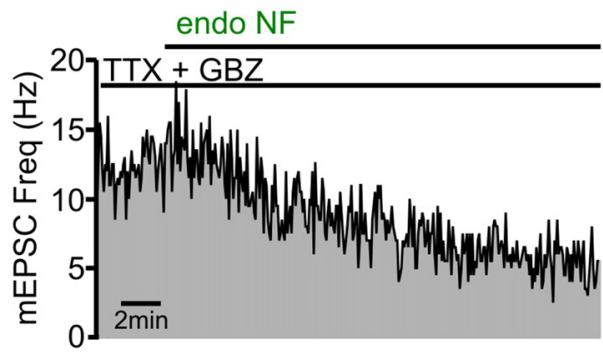

Dii

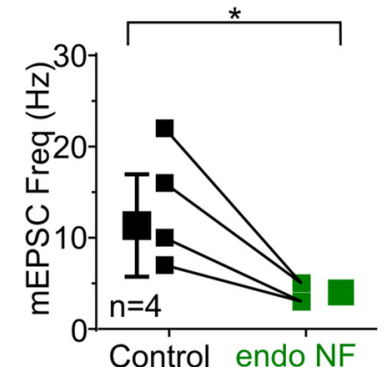

Diii

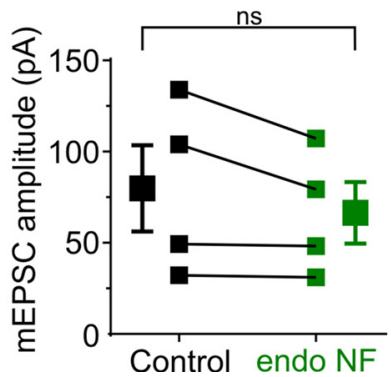

Figure 7. polySia removal in the NTS reduces glutamatergic synaptic input. A, Typical current traces of monosynaptically connected NTS neurons with eEPSCs generated following viscerosensory afferent stimulation ( $5 \mathrm{~Hz}$ ) before (black) and after (green) endoNF incubation. Individual trials are represented in gray and light green, respectively. Ai, Aii, Grouped data show that enzymatic digestion of polySia increased latency by $34.2 \%(\boldsymbol{A i}, p=0.0098, n=9)$ and decreased eEPSC amplitude by $54.4 \%(\boldsymbol{A i i}, p=0.0002, n=9)$. $\boldsymbol{B}$, Typical current traces of sEPSCs in monosynaptically connected NTS neurons before (black) and after (green) endoNF incubation. Bi, Bii, Grouped data show that removal of polySia decreased frequency by $47.2 \%(p=0.0074, n=5)$ and amplitude by $26 \%(p=0.034, n=5)$. C, Current trace of NMDA-mediated sustained currents in monosynaptically connected NTS neurons before (black) and after (green) endoNF incubation. Ci, Sustained current $100 \mathrm{~ms}$ (hashed vertical line) after initial stimulus. Cii, Grouped data show that enzymatic digestion of polySia increased sustained current by $42 \%(p=0.0031, n=4)$ in response to high-frequency stimulation of the solitary tract. Stimulus artifacts and current response to first shock were truncated to aid visual representation. $D$, Current traces showing mEPSCs recorded before (black) and after endoNF treatment (green) with both TTX and GBZ present in the bath. CNQX (gray) was added to the superfusate at the end of experimentation. Di, Frequency distribution over time shows a progressive decrease in mEPSC frequency (10 s bins) following addition of endoNF to the perfusate. Dii, Diii, Grouped data show that enzymatic digestion of polySia decreased frequency by $71 \%(p=0.04, n=4)$ but had no effect on mEPSC amplitude $(p=0.156, n=4)$. Data are mean \pm SEM. ${ }^{*} p<0.05 ;{ }^{* *} p<0.01 ;{ }^{* * *} p<0.001 ; \mathrm{ns}, p>0.05$. 
$0.53 \pm 0.08$ vs $\left.0.58 \pm 0.05, t_{(5)}=1.54, p=0.18, n=6\right)$, and eEPSC decay tau $\left(\mathrm{T}_{90 \%-10 \%} ; 5.67 \pm 1.70 \mathrm{~ms}\right.$ vs $5.65 \pm 0.60 \mathrm{~ms}$, $\left.t_{(5)}=0.30, p=0.78, n=6\right)$ remained unaffected following polySia digestion.

In the same neurons, we examined whether polySia was required for the maintenance of sEPSCs, arising from spontaneous glutamate release. Enzymatic digestion of polySia significantly decreased both the frequency of sEPSC by $58.80 \%$ (3.80 \pm 2.30 $\mathrm{Hz}$ vs $\left.7.70 \pm 2.80 \mathrm{~Hz}, t_{(4)}=5.01, p=0.0074, n=5\right)$, and amplitude by $27.80 \%\left(22.34 \pm 5.10 \mathrm{pA}\right.$ vs $30.21 \pm 3.65 \mathrm{pA}, t_{(4)}=$ $3.18, p=0.034, n=5$; Fig. $7 B, B i i)$. Together, these data indicate the importance of polySia expression within the NTS in facilitating excitatory synaptic transmission from viscerosensory afferents mediated by AMPA receptor activation.

In a subset of monosynaptically connected neurons, we investigated the effect of polySia removal on NMDA-mediated sustained currents, recently identified in second-order NTS neurons (Zhao et al., 2015). Neurons were voltage clamped at $-60 \mathrm{mV}$ and recorded in $\mathrm{Mg}^{2+}$-free aCSF to remove the $\mathrm{Mg}^{2+}$ block on NMDA receptors (Mayer et al., 1984). In 4 of 5 neurons tested, stimulating the solitary tract at $50 \mathrm{~Hz}$ consistently evoked large sustained currents (Fig. $7 \mathrm{C}, \mathrm{Ci}$ ), that were not observed at lower stimulating frequencies $(1 \mathrm{~Hz}$, data not shown). Enzymatic digestion of polySia increased the current generated to high-frequency stimulation of the solitary tract by $42 \pm 4.80 \%\left(t_{(3)}=8.758\right.$, $p=0.0031, n=4$; Fig. 7Cii).

Collectively, these data suggest that the fidelity of excitatory synaptic transmission during high- and low-frequency afferent input is maintained by polySia expression, and that its removal may alter the appropriate charge required to open and close AMPA and NMDA receptors as previously suggested (Vaithianathan et al., 2004; Hammond et al., 2006).

\section{polySia contributes to presynaptic glutamate release in the NTS}

To determine whether polySia removal impacts neurotransmission postsynaptically or presynaptically we recorded, in the presence of TTX $(10 \mu \mathrm{M})$ and GBZ $(25 \mu \mathrm{M})$, mEPSCs, and measured responses before and during polySia digestion (Fig. $7 D, D i$ ). Enzymatic digestion of polySia decreased mEPSC frequency by $68.75 \%$ (endoNF, $4.00 \pm 0.57 \mathrm{~Hz}$ vs control, $13.75 \pm 3.30, t_{(3)}=$ 3.47, $p=0.040, n=4$; Fig. $7 \mathrm{Dii})$ without altering amplitude $\left(62.00 \pm 15.70 \mathrm{pA}\right.$ vs $74.50 \pm 22.08 \mathrm{pA}, t_{(3)}=1.88, p=0.156, n=$ 4; Fig. 7Diii). CNQX was added at the end of experimentation demonstrating that mEPSCs were dependent on non-NMDAtype glutamate receptors (Fig. $7 D$ ). These data indicate that removal of polySia reduces glutamatergic release from presynaptic terminals at NTS neurons, and this mechanism likely contributes to the reduction in viscerosensory afferent transmission (both evoked and spontaneous) seen following polySia digestion.

\section{Enzymatic cleavage of polySia within the NTS increases sympathetic nerve discharge in vivo}

Finally, as multiple pathways emerge from the NTS that influence presympathetic neurons regulating the sympathetic outflow (Guyenet, 2006), we determined whether the changes to intrinsic neuronal properties and/or viscerosensory afferent transmission resulting from polySia digestion within the NTS in vitro, would be sufficient to alter function in vivo. sSNA and arterial pressure recorded before and after microinjection of neuraminidases directly into the caudal and intermediate NTS, in urethaneanesthetized rats. Bilateral microinjections of endoNF $(2 \mu \mathrm{g} / \mu \mathrm{l}$, total volume $800 \mathrm{nl}$ ) elicited sympathoexcitation (Fig. $8 A ; F_{(1,8)}=$
34.06, $p=0.0004)$ with peak increases in sSNA of $140.80 \pm$ $7.63 \%$ compared with control (saline, $96.50 \pm 4.48 \%, t_{(104)}=$ 4.991, $p<0.0001, n=6$; Fig. $8 A i$ ). Brains were removed at the end of each experiment and the degree of polySia digestion determined using Western blot analysis. polysia was present following PBS microinjection but absent following endoNF microinjection ( $0.94 \pm 0.05$ a.u. vs $0.09 \pm 0.02$ a.u., $t_{(21)}=5.71, p<$ $0.0001, n=6$; Fig. 8 Bi,Biv). Microinjection of the neuraminidase targeting only terminal $\alpha 2-3$ and $\alpha 2-6$ sialic acids $(\alpha 2-3+\alpha 2-6$ Neu, $0.1 \mathrm{U} / \mu \mathrm{l})$ had no effect on $\operatorname{sSNA}\left(F_{(1,8)}=2.580, p=0.15\right.$, $n=5$; Fig. $8 A, A i)$ and similarly did not alter the expression of polySia relative to control $\left(t_{(21)}=0.81, p>0.99, n=5\right.$; Fig. 8Bii,Biv).

polySia also terminates $\alpha 2-3$ and $\alpha 2-6$ sialic acid-linked glycans (Schnaar et al., 2014), which would be untouched by $\alpha 2-3+\alpha 2-6$ $\mathrm{Neu}$; we therefore determined the combined effect of enzymatically removing polySia together with $\alpha 2-3$ - and $\alpha 2-6$-linked sialic acid residues by combining both enzymes $(\alpha 2-3+\alpha 2-6 \mathrm{Neu}+$ endoNF). Microinjection of the combined enzymes bilaterally caused rapid sympathoexcitation (Fig. $8 A ; F_{(1,7)}=20.43, p=0.0027$ ) with a peak effect of $162.50 \pm 13.73 \%\left(t_{(91)}=4.760, p<0.0001, n=5\right.$; Fig. $8 \mathrm{Ai}$ ) and in support of a specific role for polySia, no polySia was detected at the protein level $(0.01 \pm 0.002$ a.u. vs $0.94 \pm 0.05$ a.u., $t_{(21)}=5.90, p<0.0001, n=5$; Fig. 8Biii,Biv). Similarly, microinjection of $\mathrm{Neu}(0.1 \mathrm{U} / \mu \mathrm{l})$ also produced rapid sympathoexcitation $\left(F_{(1,8)}=68.18, p<0.0001\right)$ and peaked at a higher level $(179.33 \pm$ $14.56 \%, t_{(104)}=4.315, p=0.0005, n=6$; Fig. $\left.9 A, A i\right)$ that was significantly greater than endoNF alone ( $p=0.041$, Mann-Whitney $U$ test, $n=6$; Fig. 9B) but did not differ from that evoked by $\alpha 2-3+$ $\alpha 2-6 \mathrm{Neu}+$ endoNF ( $p=0.628$, Mann-Whitney $U$ test, $n=5$ ).

The effects on arterial pressure were more variable following enzymatic digestion of polySia. Neu evoked the largest and most rapid sympathoexcitation (see above) which acutely elevated mean arterial pressure (MAP) compared with control (15 min: $152 \pm 10.97$ vs $87.75 \pm 7.32 \mathrm{mmHg}, t_{(13)}=4.425, p=0.0014$, $n=6$; Fig. $9 A, B, C i)$. This MAP increase however, returned to baseline within $60 \mathrm{~min}\left(108 \pm 3.1\right.$ vs $92.5 \pm 7.5 \mathrm{mmHg}, t_{(13)}=$ 1.91, $p=0.157, n=6$; Fig. 9Cii). As endoNF evoked smaller and slower sympathoexcitation, little to no effect on MAP was seen acutely (15 min: $98.24 \pm 9.11$ vs $87.75 \pm 7.32 \mathrm{mmHg}, t_{(13)}=$ 0.713, $p=0.97, n=6$; Fig. $9 \mathrm{Ci})$ or at $60 \mathrm{~min}(95.02 \pm 6.38 \mathrm{vs}$ $92.5 \pm 7.5 \mathrm{mmHg}, t_{(13)}=0.301, p>0.99, n=6$; Fig. 9Cii).

Together these results demonstrate that removal of polySia in the NTS increases sympathetic nerve activity, which is consistent with a net disfacilitation in the NTS or experimental visceral deafferentation (Iggo and Vogt, 1962; Fagius et al., 1985). Thus, our findings indicate that polySia expression within the NTS is required to maintain appropriate (i.e., "normal") levels of sympathetic outflow. Figure 10 depicts the cellular mechanisms and network effects modified by polySia in the NTS highlighting the consequences of polysia's removal.

\section{Discussion}

We demonstrate that polySia expression in the dorsal medulla is required for normal excitatory neurotransmission within the NTS, and that its disruption is sufficient to acutely increase sympathetic outflow. We draw these conclusions based on the following observations: First, neurons in the NTS were ensheathed by polySia, expressed predominantly in or on the fine processes of astrocytes and within the extracellular space. Second, enzymatic removal of polySia-enhanced currents in NTS neurons, mediated by changes at IKDR and BK channels, and altered release of $\mathrm{Ca}^{2+}$ from internal stores. Third, enzymatic removal of 

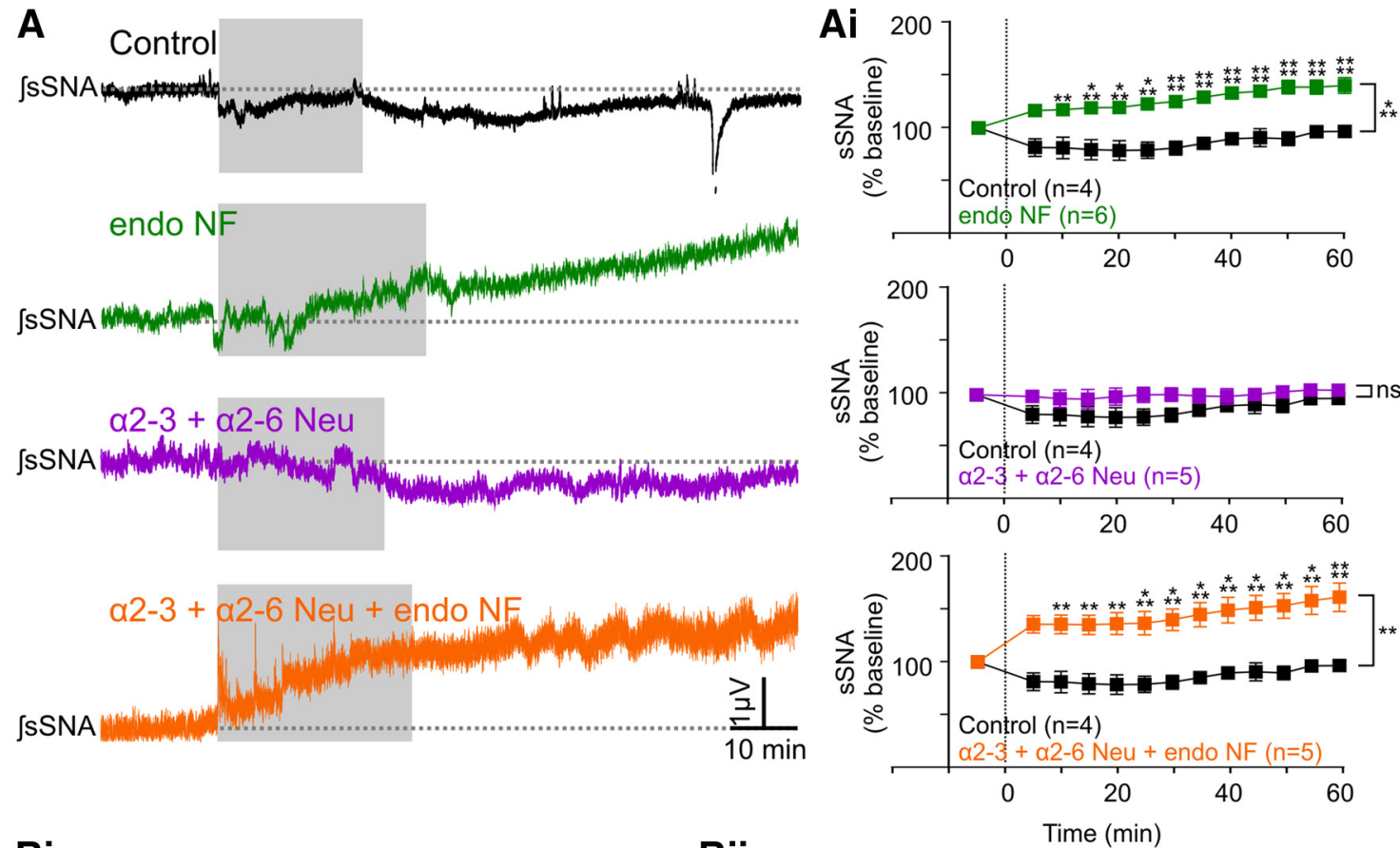

Bi

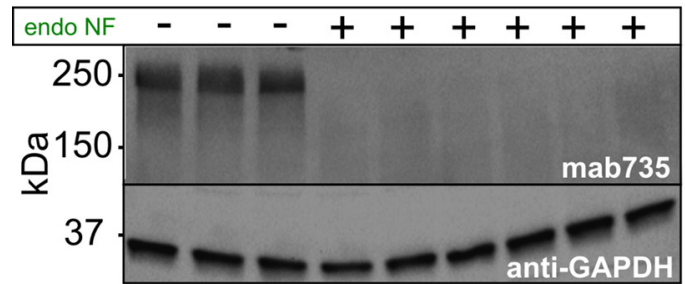

Bii

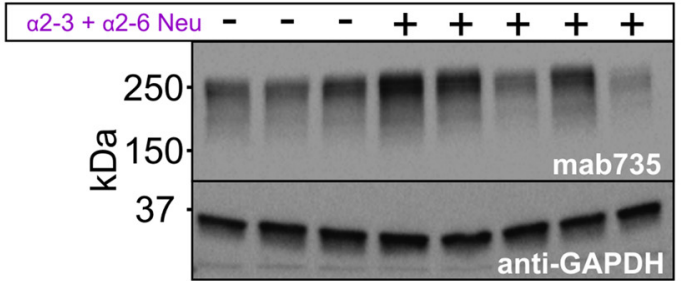

\section{Biii}
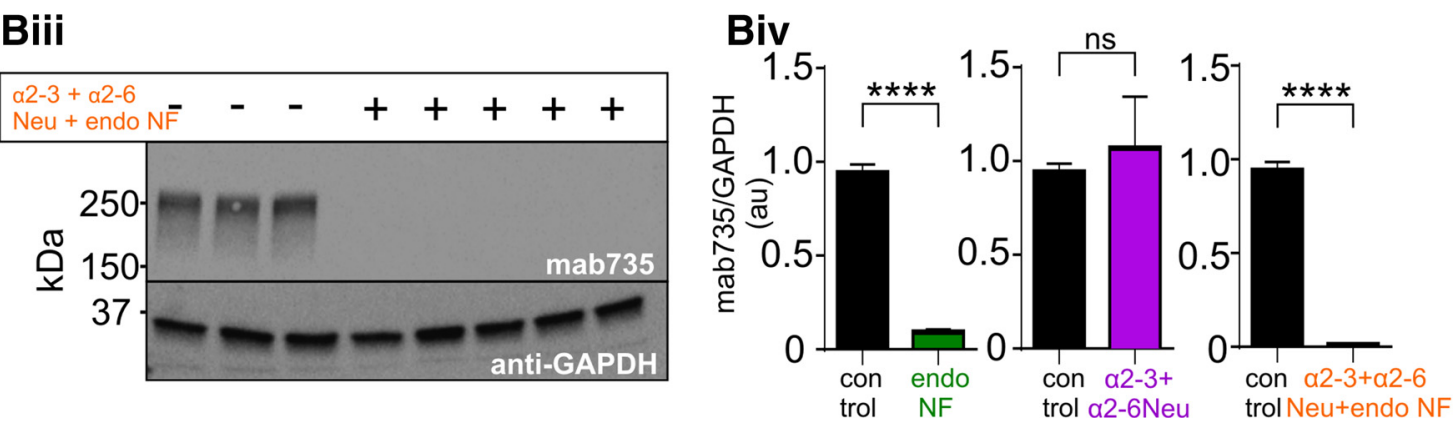

Figure 8. polySia removal in the NTS increases sympathetic nerve activity. $A$, Integrated and smoothed representative traces of $5 S$ NA recorded in urethane-anesthetized, paralyzed, and ventilated rats following saline (black), endoNF (green $2 \mu \mathrm{g} / \mu \mathrm{l}), \alpha 2-3+\alpha 2-6$ Neu (magenta, $0.1 \mathrm{U} / \mu \mathrm{l})$, or $\alpha 2-3+\alpha 2-6$ Neu + endoNF (orange) microinjections bilaterally into the NTS. Gray represents the period of injection. $A i$, Grouped data show that endoNF $(n=6)$ and $\alpha 2-3+\alpha 2-6$ Neu + endoNF $(n=5)$ significantly increased sSNA by $40.8 \%$ and $62.5 \%$, respectively $(p<$ 0.0001). Microinjection of $\alpha 2-3+\alpha 2-6$ Neu alone had no effect compared with control $(p=0.15, n=5)$. $\boldsymbol{B}$, Western blots of NTS dissected from the animals in (Ai) following microinjection of control, endoNF (Bi, $2 \mu \mathrm{g} / \mu \mathrm{l}$, green), $\alpha 2-3+\alpha 2-6 \mathrm{Neu}$ (Bii, $0.1 \mathrm{U} / \mu \mathrm{l}$, magenta), or $\alpha 2-3+\alpha 2-6 \mathrm{Neu}+$ endoNF (Biii, orange). Biv, Grouped data showing quantitative changes in polySia protein (detected using Mab735) from animals in $\boldsymbol{B}$. polySia-ir was virtually absent following microinjection of either endoNF (green box, $p<0.0001, n=6$ ) or $\alpha 2-3+\alpha 2-6$ Neu + endoNF (orange box, $p<0.0001, n=5$ ), and was not altered following microinjection of $\alpha 2-3+\alpha 2-6$ Neu alone (magenta box, $p>0.99, n=5$ ). Data are mean \pm SEM. ${ }^{* *} p<0.01$; ${ }^{* * *} p<0.001$; $* * * * 0<0.0001 ; n s, p>0.05$.

polySia reduced AMPA-mediated excitatory transmission following viscerosensory afferent stimulation by decreasing evoked EPSCs, attenuating action potential generation and propagation and diminishing spontaneous and mEPSCs, whereas highfrequency stimulus-evoked NMDA-dependent sustained currents were increased. Finally, enzymatic removal of polySia from the NTS in vivo increased splanchnic sympathetic nerve activity, whereas microinjection of sialidases that do not target polySia had little effect. Collectively, our studies indicate that polySia plays a hitherto unrecognized role in the modulation of neural transmission within the NTS, and demonstrate that polySia expression is required for the appropriate processing of viscerosensory afferent activity and its transmission to downstream networks, including the sympathetic outflow.

We extend earlier studies that describe the location of polySia in the CNS (Bonfanti et al., 1992; Bouzioukh et al., 2001a, b) demonstrating abundant polySia expression throughout the rostrocaudal extent of the NTS. Our ultrastructural analysis revealed polySia expression at sites that influence neurotransmission: in the extracellular space and intricate processes of astrocytes that 
A
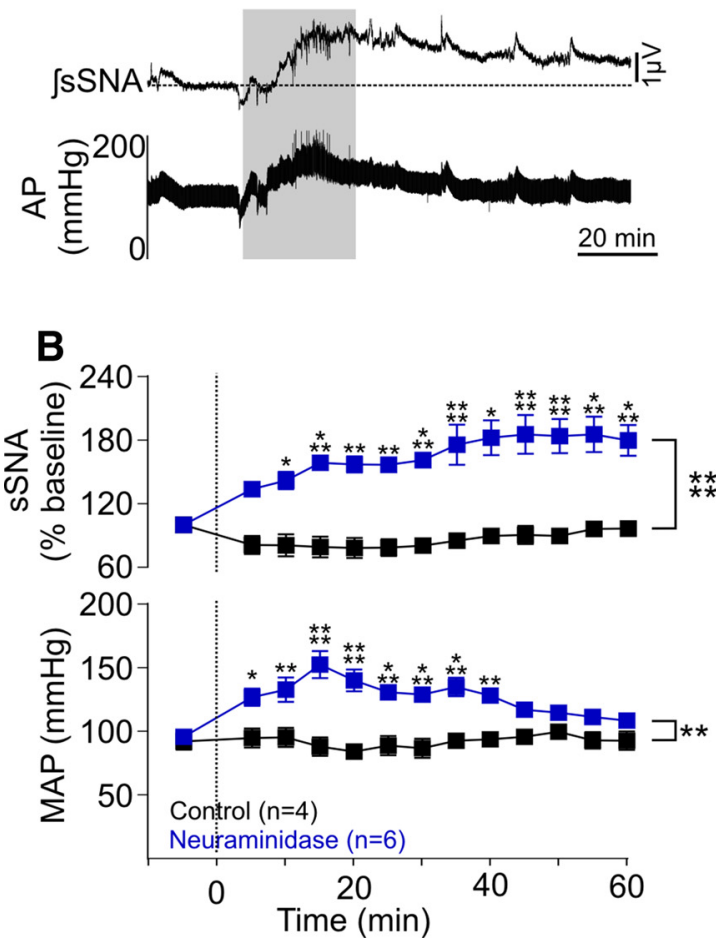
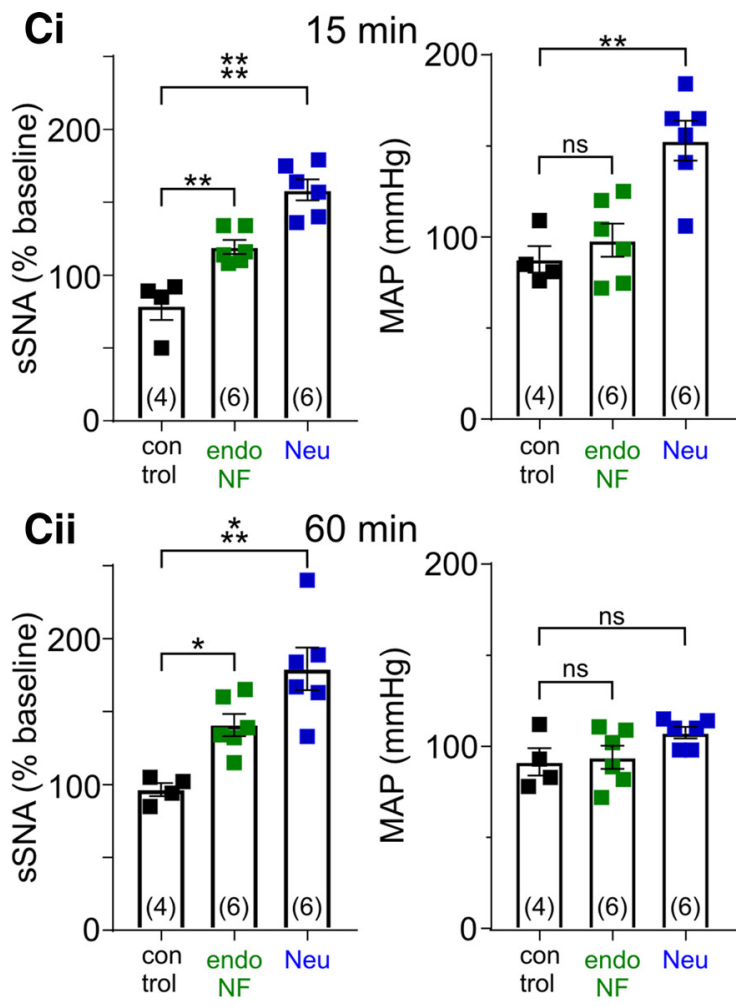

Figure 9. Removal of all sialic acids in the NTS causes rapid sympathoexcitation and acute hypertension. $A$, Representative traces of integrated and smoothed neurogram of s SNA and arterial pressure following $\mathrm{Neu}$ (blue, $0.1 \mathrm{U} / \mu \mathrm{l}$ ) or saline (control) microinjected into the NTS. Gray represents the period of injection. $\boldsymbol{B}$, Grouped data show the time course of response in sSNA and MAP following Neu microinjection $(n=6)$. SSNA increased by $79.3 \%(p<0.0001)$ and arterial pressure increased acutely $(p=0.0014)$, returning to baseline after $60 \mathrm{~min}(p=0.157)$. Ci, Grouped data at $15 \mathrm{~min}$ after injection show that, compared with control, Neu significantly increased sSNA (158.5 $\pm 1.2 \mu \mathrm{V}, p<0.0001, n=6)$ and MAP $(152.8 \pm 10.9 \mathrm{mmHg}, p=0.0014)$, whereas endoNF evoked a smaller increase in SSNA (119.3 $\pm 4.80 \%, p=0.0039, n=6)$ but did not change MAP $(98.24 \pm 9.12 \mathrm{mmHg}, p=0.977)$. Cii, Grouped data at 60 min after injection show that, compared with control, both Neu and endoNF increased SSNA (179.3 \pm 14.56 and $140.80 \pm 7.63 \mu \mathrm{V}, p=0.0004$ and $p=0.0357$, respectively) but had no significant effect on MAP (108.5 \pm 3.12 and $95.02 \pm 6.40 \mathrm{mmHg}, p=0.157$ and $p>0.99$, respectively). Data are mean \pm SEM. ${ }^{*} p<0.05 ;{ }^{* *} p<0.01 ;{ }^{* * *} p<0.001 ;{ }^{* * *} p<0.0001 ; n s, p>0.05$.

envelop neurons and synapses, as well as in some dendrites and axon terminals, consistent with our synaptophysin/polySia double labeling (Fig. 10A). Supporting our finding of polySia expression in astrocytic fine processes, blockade of microtubular function in the neurosecretory hypothalamus caused accumulation of polySia in astrocyte cell bodies (Theodosis et al., 1999, 2008). Expression around neurons found here is consistent with previous studies in the hippocampus, striatum, and cortex where polySia is linked with synaptic plasticity (Muller et al., 1996; Uryu et al., 1999; Eckhardt et al., 2000; Hildebrandt and Dityatev, 2015). Enzymatic digestion of polySia has no effect on presynaptic or postsynaptic neuronal structures examined by electron microscopy (Theodosis et al., 1999; Brusés et al., 2002), suggesting that functional effects result from disruption of signaling mechanisms, rather than major morphological changes.

In exploring the cellular mechanisms influenced by polySia in the NTS, we found that enzymatic removal of polySia increased TEA-sensitive currents, inhibited the closure of BK channels, and produced effects consistent with the increased release of $\mathrm{Ca}^{2+}$ from intracellular stores (Fig. 10A). The effects of TEA differed to those of Ibtx, indicating effects at multiple $\mathrm{K}^{+}$channels, including at delayed rectified $\mathrm{K}^{+}$channels, common in NTS neurons (Andresen and Kunze, 1994). Functional effects of NTS desialylation were not unexpected given that voltage-gated $\mathrm{K}^{+}$channels present on NTS neurons are heavily glycosylated, often with glycans likely capped by sialic acids (Cartwright and Schwalbe, 2009; Ednie and Bennett, 2012). A range of effects of desialylation have been described in other cell types, including both depolarizing and hyperpolarizing shifts in channel activation (Ednie and Bennett, 2012; Scott and Panin, 2014), which appear dependent upon the cell type examined and the channel isoform investigated. These complications arise as desialylation of the same ion channel in different cell types can produce varying effects (Ednie and Bennett, 2012; Scott and Panin, 2014) and channel isoforms can also vary in the glycan structures they carry (Schwalbe et al., 2008). Curiously astrocytes express abundant voltage-gated $\mathrm{K}^{+}$channels (Contet et al., 2016), so it is possible that polysialylation may also impact $\mathrm{K}^{+}$ spatial buffering. Although both sialic acids and polySia are associated with voltage-gated $\mathrm{Na}^{+}$channels in rat brain (Zuber et al., 1992; Bennett et al., 1997; Ednie and Bennett, 2012) we saw no impact of polySia removal on action potential properties generated by current injection or following afferent stimulation.

We found that removal of polySia disrupted information transfer from viscerosensory afferents as evoked and spontaneous AMPA-dependent EPSCs were reduced, and NMDA sustained currents increased, indicating a role for polysia in regulating excitatory neurotransmission (Fig. 10A). As viscerosensory afferents innervate both somata and dendrites of NTS neurons (Anders et al., 1993), the astrocytic, neuronal, and extrasynaptic location of polySia seen here, together with the close association with synaptophysin shown by us and others (Bouzioukh et al., 2001a), are consistent with such a role. It is plausible that polySia on astrocytes may also influence synaptic or extrasynaptic glutamate availability as astrocytes express abundant glutamate transporters such as EAAT2 responsible for $90 \%$ of glutamate reuptake in brain. 


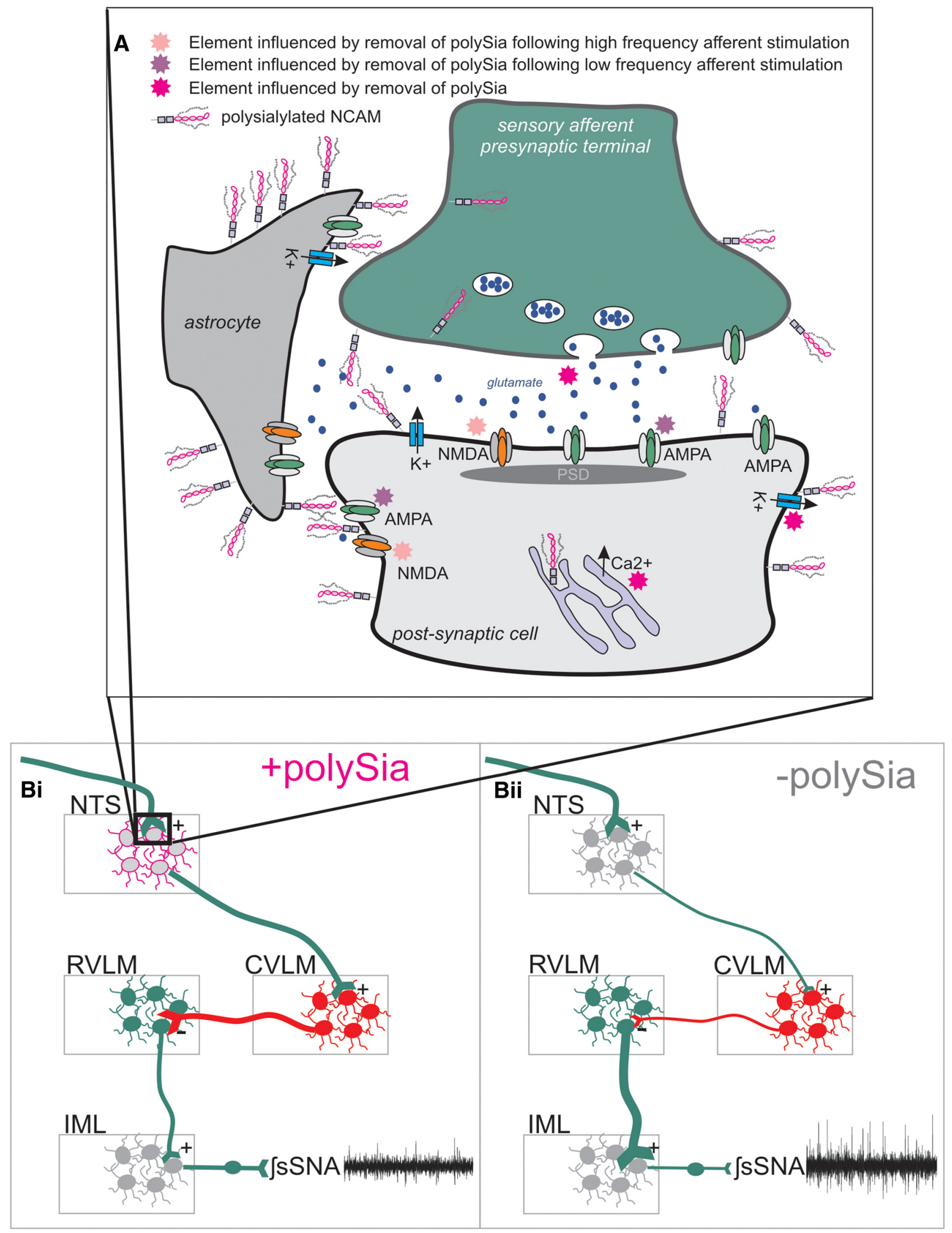

Figure 10. Overview depicting the structural location of polySia as well as the cellular mechanisms modified and functional consequences following removal of polySia from the NTS. $A$, Astrocytic, terminal, and extrasynaptic expression of polySia influences Kv, intracellular calcium, and viscerosensory afferent glutamatergic transmission: during low-frequency input (magenta stars), and high input (pink stars), maintaining appropriate transmission through the NTS. B, Schematically, the local and network impact of polySia in the NTS under in vivo (Figure legend continues.) 
Within the NTS, variations in synaptic strength usually result from differences in the number of contact or release sites between afferent axons and postsynaptic membranes, rather than glutamate release probability or uptake capacity (Bailey et al., 2006b; Peters et al., 2008). Reduced action potential generation has been demonstrated in the NTS when $\mathrm{K}^{+}$channels are activated before viscerosensory afferent stimulation (Bailey et al., 2006a, 2007), or when glutamate release sites from single afferents are reduced (Bailey et al., 2006b). It appears paradoxical that polySia is not present within synapses in the NTS, given that its removal perturbs all forms of afferent excitation (e/s/mEPSC). However, polySia likely modulates transmission via effects directly at $\mathrm{K}^{+}$ channels, and/or by altering availability of glutamate to the postsynaptic density, or via mechanisms at multiple release site recently described in NTS neurons (Fawley et al., 2016).

Also in keeping with effects seen here on evoked transient and sustained currents, polySia can modulate AMPA and NMDA receptor function (Vaithianathan et al., 2004; Hammond et al., 2006; Varbanov and Dityatev, 2017). Both receptor types are present within the NTS and are activated by differing afferent input (Aylwin et al., 1997; Zhang and Mifflin, 1998), with lowfrequency stimulation evoking a large transient AMPA-mediated current (Andresen and Yang, 1990), and high-frequency stimulation $(>5 \mathrm{~Hz}$ ) a sustained NMDA-mediated current (Zhao et al., 2015). In support of our findings, activation of AMPA receptors in reconstituted lipid bilayers, in the presence of bacterially derived polySia, potentiated currents $(\sim 67 \%)$ and increased the opening probability of these receptors $(\sim 360 \%)$ (Vaithianathan et al., 2004), with opposing effects observed at NMDA receptors (decreased opening probability in the presence of polySia) (Hammond et al., 2006). Our findings therefore support previous suggestions that the anionic charge of polySia directly influences the positive amino acid residues of AMPA and NMDA receptors, as suggested for other polyanionic polysaccharides, such as heparin (Hall et al., 1996; Sinnarajah et al., 1999) and dextran (Suppiramaniam et al., 2006; Chicoine and Bahr, 2007). Whether GluN2B subunits containing NMDA receptors are targeted by removal of polySia as found previously (Kochlamazashvili et al., 2010) remains to be determined. Nevertheless, it is plausible that the anionic polySia provides optimal conditions for regulating glutamatergic transmission in the NTS.

The effects seen following polySia removal at the single neuron strongly support our findings in the whole animal, where enzymatic removal of polySia from the NTS region increased splanchnic sympathetic nerve activity (Fig. 10B). This finding is consistent with net disfacilitation of the NTS, effectively reducing information throughput resulting in sympathoexcitation via increased activity of premotor neurons (Pilowsky and Goodchild, 2002). Baroreceptor afferents provide tonic activation of the NTS altering activity on a heartbeat to heartbeat basis. Under basal conditions (as recorded here), baroreceptor firing frequency is low, favoring AMPA receptor activation with minimal input from NMDA receptors (Seagard et al., 1990; Gordon and Leone, 1991). When baroreceptor afferent traffic is reduced, sympathetic nerve activity increases (Sved et al., 1997) suggesting that

\section{$\leftarrow$}

(Figure legend continued.) conditions. Control conditions (Bi) and highlight effects (Bii) following removal of polySia. Under both conditions, afferent input remains constant (equal line weight); however following removal of polySia, neurotransmission through the NTS is attenuated and intrinsic properties are modified, reducing the gating provided by the inhibitory CVLM on tonically active sympathoexcitatory premotor RVLM neurons resulting in elevated sympathetic nerve activity.
polySia could influence such transmission. The inverse relationship between vagal afferent traffic and polySia expression in the NTS previously described (Bouzioukh et al., 2001a, b), and the sympathoexcitatory effect evoked by polySia removal seen here, appears to provide a mechanism to explain why stimulation of vagal afferents increases lumbar sympathetic nerve activity (Sun and Guyenet, 1987). The lack of a consistent blood pressure response following removal of polySia may be due to a threshold effect where blood pressure is not increased by the small, slow changes in sympathetic nerve activity induced by endo $\mathrm{N}$ alone, whereas Neu induced larger and more rapid changes in sympathetic nerve activity elevating blood pressure. Alternatively, polySia removal in the NTS may result in opposing changes in different vascular beds or influence splanchnic sympathetic fibers that innervate targets other than the vasculature. Nevertheless, the data indicate that sympathetic outflow is dependent on the expression of polySia within the NTS, which can be modified by changes to viscerosensory afferent traffic.

Targeting polySia consistently evoked sympathoexcitation. However, effects were enhanced by exo-neuraminidases that target $\alpha 2-3, \alpha 2-6$, in addition to $\alpha 2-8$ linked sialic acids, suggesting a role for other types of sialylation in regulating sympathetic outflow. However, endoNF only cleaves polySia polymers of five to eight $\alpha 2-8$ linked sialic acids (Stummeyer et al., 2005), potentially leaving some sialic acids (including single, di, or oligo sialic acids) that could be cleaved by the other enzymes used. Our Western blotting would not have detected these residual sialic acids because Mab735 recognizes octamers of $\alpha 2-8$ linked sialic acids (Evans et al., 1995; Nagae et al., 2013).

Collectively, our data show that removal of polySia alters neuronal properties and transmission of viscerosensory excitatory traffic through the NTS and that these effects alter transmission to downstream networks increasing sympathetic outflow (Fig. 10). This study expands the repertoire of signaling molecules, particularly those located on the cell surface or in astrocytes, which influence information transfer within sensory nuclei. The NTS governs autonomic, hormonal, and behavioral activity indicative of the wide spectra of functions that polySia may impact (Craig, 2003). Furthermore, the findings described here may define the neuronal mechanisms modified by polySia in higher brain regions (Rutishauser and Landmesser, 1996; Rutishauser, 2008) as well as at several sensory nuclei expressing abundant polySia (Bonfanti et al., 1992; El Maarouf et al., 2005). Finally, we demonstrate the importance of glycosylation modifications, such as sialylation, in altering neuronal function and show the importance of the level of polySia expression for appropriate information processing in the dorsal medulla, which ultimately regulates the activity of multiple downstream neural networks.

\section{References}

Aicher SA, Kurucz OS, Reis DJ, Milner TA (1995) Nucleus tractus solitarius efferent terminals synapse on neurons in the caudal ventrolateral medulla that project to the rostral ventrolateral medulla. Brain Res 693:51-63. CrossRef Medline

Anders K, Ohndorf W, Dermietzel R, Richter DW (1993) Synapses between slowly adapting lung stretch receptor afferents and inspiratory betaneurons in the nucleus of the solitary tract of cats: a light and electron microscopic analysis. J Comp Neurol 335:163-172. CrossRef Medline

Andresen MC, Kunze DL (1994) Nucleus tractus solitaries: gateway to neural circulatory control. Annu Rev Physiol 56:93-116. CrossRef Medline

Andresen MC, Paton JF (2011) The nucleus of the solitary tract. In: Processing information from viscerosensory afferents. Oxford: Oxford UP.

Andresen MC, Yang MY (1990) Non-NMDA receptors mediate sensory afferent synaptic transmission in medial nucleus tractus solitarius. Am J Physiol 259:H1307-H1311. Medline 
Appleyard SM, Marks D, Kobayashi K, Okano H, Low MJ, Andresen MC (2007) Visceral afferents directly activate catecholamine neurons in the solitary tract nucleus. J Neurosci 27:13292-13302. CrossRef Medline

Aylwin ML, Horowitz JM, Bonham AC (1997) NMDA receptors contribute to primary visceral afferent transmission in the nucleus of the solitary tract. J Neurophysiol 77:2539-2548. Medline

Bailey TW, Hermes SM, Andresen MC, Aicher SA (2006a) Cranial visceral afferent pathways through the nucleus of the solitary tract to caudal ventrolateral medulla or paraventricular hypothalamus: target-specific synaptic reliability and convergence patterns. J Neurosci 26:11893-11902. CrossRef Medline

Bailey TW, Jin YH, Doyle MW, Smith SM, Andresen MC (2006b) Vasopressin inhibits glutamate release via two distinct modes in the brainstem. J Neurosci 26:6131-6142. CrossRef Medline

Bailey TW, Hermes SM, Whittier KL, Aicher SA, Andresen MC (2007) A-type potassium channels differentially tune afferent pathways from rat solitary tract nucleus to caudal ventrolateral medulla or paraventricular hypothalamus. J Physiol 582:613-628. CrossRef Medline

Bennett E, Urcan MS, Tinkle SS, Koszowski AG, Levinson SR (1997) Contribution of sialic acid to the voltage dependence of sodium channel gating: a possible electrostatic mechanism. J Gen Physiol 109:327-343. CrossRef Medline

Bonfanti L (2006) PSA-NCAM in mammalian structural plasticity and neurogenesis. Prog Neurobiol 80:129-164. CrossRef Medline

Bonfanti L, Olive S, Poulain DA, Theodosis DT (1992) Mapping of the distribution of polysialylated neural cell adhesion molecule throughout the central nervous system of the adult rat: an immunohistochemical study. Neuroscience 49:419-436. CrossRef Medline

Bou Farah L, Bowman BR, Bokiniec P, Karim S, Le S, Goodchild AK, McMullan S (2016) Somatostatin in the rat rostral ventrolateral medulla: origins and mechanism of action. J Comp Neurol 524:323-342. CrossRef Medline

Bouzioukh F, Tell F, Jean A, Rougon G (2001a) NMDA receptor and nitric oxide synthase activation regulate polysialylated neural cell adhesion molecule expression in adult brainstem synapses. J Neurosci 21:4721-4730. Medline

Bouzioukh F, Tell F, Rougon G, Jean A (2001b) Dual effects of NMDA receptor activation on polysialylated neural cell adhesion molecule expression during brainstem postnatal development. Eur J Neurosci 14: 1194-1202. CrossRef Medline

Browning KN, Travagli RA (2010) Plasticity of vagal brainstem circuits in the control of gastric function. Neurogastroenterol Motil 22:1154-1163. CrossRef Medline

Browning KN, Travagli RA (2014) Central nervous system control of gastrointestinal motility and secretion and modulation of gastrointestinal functions. Compr Physiol 4:1339-1368. CrossRef Medline

Brusés JL, Chauvet N, Rubio ME, Rutishauser U (2002) Polysialic acid and the formation of oculomotor synapses on chick ciliary neurons. J Comp Neurol 446:244-256. CrossRef Medline

Burke PG, Li Q, Costin ML, McMullan S, Pilowsky PM, Goodchild AK (2008) Somatostatin 2A receptor-expressing presympathetic neurons in the rostral ventrolateral medulla maintain blood pressure. Hypertension 52:1127-1133. CrossRef Medline

Cartwright TA, Schwalbe RA (2009) Atypical sialylated N-glycan structures are attached to neuronal voltage-gated potassium channels. Biosci Rep 29:301-313. CrossRef Medline

Champagnat J, Jacquin T, Richter DW (1986) Voltage-dependent currents in neurones of the nuclei of the solitary tract of rat brainstem slices. Pflugers Arch 406:372-379. CrossRef Medline

Chen X, Varki A (2010) Advances in the biology and chemistry of sialic acids. ACS Chem Biol 5:163-176. CrossRef Medline

Chicoine LM, Bahr BA (2007) Excitotoxic protection by polyanionic polysaccharide: evidence of a cell survival pathway involving AMPA receptorMAPK Interactions. J Neurosci Res 85:294-302. CrossRef Medline

Coetzee WA, Amarillo Y, Chiu J, Chow A, Lau D, McCormack T, Moreno H, Nadal MS, Ozaita A, Pountney D, Saganich M, Vega-Saenz De Miera E, Rudy B (1999) Molecular diversity of $\mathrm{K}^{+}$channels. Ann N Y Acad Sci 868:233-285. CrossRef Medline

Contet C, Goulding SP, Kuljis DA, Barth AL (2016) BK channels in the central nervous system. Int Rev Neurobiol 128:281-342. CrossRef Medline

Craig AD (2003) Interoception: the sense of the physiological condition of the body. Curr Opin Neurobiol 13:500-505. CrossRef Medline

Damanhuri HA, Burke PG, Ong LK, Bobrovskaya L, Dickson PW, Dunkley PR, Goodchild AK (2012) Tyrosine hydroxylase phosphorylation in cat- echolaminergic brain regions: a marker of activation following acute hypotension and glucoprivation. PLoS One 7:e50535. CrossRef Medline

Dekin MS, Getting PA (1987) In vitro characterization of neurons in the ventral part of the nucleus tractus solitaries: II. Ionic basis for repetitive firing patterns. J Neurophysiol 58:215-229. Medline

Dekin MS, Getting PA, Johnson SM (1987) In vitro characterization of neurons in the ventral part of the nucleus tractus solitaries: I. Identification of neuronal types and repetitive firing properties. J Neurophysiol 58:195214. Medline

Doyle MW, Andresen MC (2001) Reliability of monosynaptic sensory transmission in brain stem neurons in vitro. J Neurophysiol 85:22132223. Medline

Eckhardt M, Bukalo O, Chazal G, Wang L, Goridis C, Schachner M, GerardySchahn R, Cremer H, Dityatev A (2000) Mice deficient in the polysialyltransferase ST8SiaIV/PST-1 allow discrimination of the roles of neural cell adhesion molecule protein and polysialic acid in neural development and synaptic plasticity. J Neurosci 20:5234-5244. Medline

Ednie AR, Bennett ES (2012) Modulation of voltage-gated ion channels by sialylation. Compr Physiol 2:1269-1301. CrossRef Medline

El Maarouf A, Kolesnikov Y, Pasternak G, Rutishauser U (2005) Polysialic acid-induced plasticity reduces neuropathic insult to the central nervous system. Proc Natl Acad Sci U S A 102:11516-11520. CrossRef Medline

Evans SV, Sigurskjold BW, Jennings HJ, Brisson JR, To R, Tse WC, Altman E, Frosch M, Weisgerber C, Kratzin HD (1995) Evidence for the extended helical nature of polysaccharide epitopes: the 2.8 A resolution structure and thermodynamics of ligand binding of an antigen binding fragment specific for alpha-(2->8)-polysialic acid. Biochemistry 34:6737-6744. CrossRef Medline

Fagius J, Wallin BG, Sundlöf G, Nerhed C, Englesson S (1985) Sympathetic outflow in man after anaesthesia of the glossopharyngeal and vagus nerves. Brain 108:423-438. CrossRef Medline

Fawley JA Hofmann ME, Andresen MC (2016) Distinct calcium sources support multiple modes of synaptic release from cranial sensory afferents. J Neurosci 36:8957-8966. CrossRef Medline

Frosch M, Görgen I, Boulnois GJ, Timmis KN, Bitter-Suermann D (1985) NZB mouse system for production of monoclonal antibodies to weak bacterial antigens: isolation of an $\operatorname{IgG}$ antibody to the polysaccharide capsules of Escherichia coli K1 and group B meningococci. Proc Natl Acad Sci U S A 82:1194-1198. CrossRef Medline

Glaum SR, Brooks PA (1996) Tetanus-induced sustained potentiation of monosynaptic inhibitory transmission in the rat medulla: evidence for a presynaptic locus. J Neurophysiol 76:30-38. Medline

Gogolla N, Galimberti I, DePaola V, Caroni P (2006) Staining protocol for organotypic hippocampal slice cultures. Nat Protoc 1:2452-2456. CrossRef Medline

Gordon FJ, Leone C (1991) Non-NMDA receptors in the nucleus of the tractus solitarius play the predominant role in mediating aortic baroreceptor reflexes. Brain Res 568:319-322. CrossRef Medline

Guyenet PG (2006) The sympathetic control of blood pressure. Nat Rev Neurosci 7:335-346. CrossRef Medline

Hall RA, Vodyanoy V, Quan A, Sinnarajah S, Suppiramaniam V, Kessler M, Bahr BA (1996) Effects of heparin on the properties of solubilized and reconstituted rat brain AMPA receptors. Neurosci Lett 217:179-183. CrossRef Medline

Hammond MS, Sims C, Parameshwaran K, Suppiramaniam V, Schachner M, Dityatev A (2006) Neural cell adhesion molecule-associated polysialic acid inhibits NR2B-containing N-methyl-D-aspartate receptors and prevents glutamate-induced cell death. J Biol Chem 281:34859-34869. CrossRef Medline

Hermes SM, Mitchell JL, Aicher SA (2006) Most neurons in the nucleus tractus solitarii do not send collateral projections to multiple autonomic targets in the rat brain. Exp Neurol 198:539-551. CrossRef Medline

Hildebrandt H, Dityatev A (2015) Polysialic acid in brain development and synaptic plasticity. Top Curr Chem 366:55-96. CrossRef Medline

Iggo A, Vogt M (1962) The mechanism of adrenaline-induced inhibition of sympathetic preganglionic activity. J Physiol 161:62-72. CrossRef Medline

Jin YH, Cahill EA, Fernandes LG, Wang X, Chen W, Smith SM, Andresen MC (2010) Optical tracking of phenotypically diverse individual synapses on solitary tract nucleus neurons. Brain Res 1312:54-66. CrossRef Medline

Kirov SA, Sorra KE, Harris KM (1999) Slices have more synapses than perfusion-fixed hippocampus from both young and mature rats. J Neurosci 19:2876-2886. Medline 
Kline DD (2008) Plasticity in glutamatergic NTS neurotransmission. Respir Physiol Neurobiol 164:105-111. CrossRef Medline

Kochlamazashvili G, Senkov O, Grebenyuk S, Robinson C, Xiao MF, Stummeyer K, Gerardy-Schahn R, Engel AK, Feig L, Semyanov A, Suppiramaniam V, Schachner M, Dityatev A (2010) Neural cell adhesion molecule-associated polysialic acid regulates synaptic plasticity and learning by restraining the signaling through GluN2B-containing NMDA receptors. J Neurosci 30: 4171-4183. CrossRef Medline

Llewellyn-Smith IJ, Dicarlo SE, Collins HL, Keast JR (2005) Enkephalinimmunoreactive interneurons extensively innervate sympathetic preganglionic neurons regulating the pelvic viscera. J Comp Neurol 488:278-289. CrossRef Medline

Mayer CA, Macklin WB, Avishai N, Balan K, Wilson CG, Miller MJ (2009) Mutation in the myelin proteolipid protein gene alters BK and SK channel function in the caudal medulla. Respir Physiol Neurobiol 169:303-314. CrossRef Medline

Mayer ML, Westbrook GL, Guthrie PB (1984) Voltage-dependent block by $\mathrm{Mg}^{2+}$ of NMDA responses in spinal cord neurones. Nature 309:261-263. CrossRef Medline

McDougall SJ, Peters JH, Andresen MC (2009) Convergence of cranial visceral afferents within the solitary tract nucleus. J Neurosci 29:1288612895. CrossRef Medline

Miles R (1986) Frequency dependence of synaptic transmission in nucleus of the solitary tract in vitro. J Neurophysiol 55:1076-1090. Medline

Moak JP, Kunze DL (1993) Potassium currents of neurons isolated from medical nucleus tractus solitarius. Am J Physiol 265:H1596-H1602. Medline

Muller D, Wang C, Skibo G, Toni N, Cremer H, Calaora V, Rougon G, Kiss JZ (1996) PSA-NCAM is required for activity-induced synaptic plasticity. Neuron 17:413-422. CrossRef Medline

Nagae M, Ikeda A, Hane M, Hanashima S, Kitajima K, Sato C, Yamaguchi Y (2013) Crystal structure of anti-polysialic acid antibody single chain Fv fragment complexed with octasialic acid: insight into the binding preference for polysialic acid. J Biol Chem 288:33784-33796. CrossRef Medline

Oltmann-Norden I, Galuska SP, Hildebrandt H, Geyer R, Gerardy-Schahn R, Geyer H, Mühlenhoff M (2008) Impact of the polysialyltransferases ST8SiaII and ST8SiaIV on polysialic acid synthesis during postnatal mouse brain development. J Biol Chem 283:1463-1471. CrossRef Medline

Parker LM, Kumar NN, Lonergan T, Goodchild AK (2013) Neurochemical codes of sympathetic preganglionic neurons activated by glucoprivation. J Comp Neurol 521:2703-2718. CrossRef Medline

Paxinos G, Watson CR (2006) The rat brain in stereotaxic coordinates. San Diego: Academic.

Pedarzani P, Kulik A, Muller M, Ballanyi K, Stocker M (2000) Molecular determinants of $\mathrm{Ca}^{2+}$-dependent $\mathrm{K}^{+}$channel function in rat dorsal vagal neurones. J Physiol 527:283-290. CrossRef Medline

Peters JH, McDougall SJ, Kellett DO, Jordan D, Llewellyn-Smith IJ, Andresen MC (2008) Oxytocin enhances cranial visceral afferent synaptic transmission to the solitary tract nucleus. J Neurosci 28:11731-11740. CrossRef Medline

Pilowsky PM, Goodchild AK (2002) Baroreceptor reflex pathways and neurotransmitters: 10 years on. J Hypertens 20:1675-1688. CrossRef Medline

Rutishauser U (2008) Polysialic acid in the plasticity of the developing and adult vertebrate nervous system. Nat Rev Neurosci 9:26-35. CrossRef Medline

Rutishauser U, Landmesser L (1996) Polysialic acid in the vertebrate nervous system: a promoter of plasticity in cell-cell interactions. Trends Neurosci 19:422-427. CrossRef Medline

Schauer R (2009) Sialic acids as regulators of molecular and cellular interactions. Curr Opin Struct Biol 19:507-514. CrossRef Medline

Schindelin J, Arganda-Carreras I, Frise E, Kaynig V, Longair M, Pietzsch T, Preibisch S, Rueden C, Saalfeld S, Schmid B, Tinevez JY, White DJ, Hartenstein V, Eliceiri K, Tomancak P, Cardona A (2012) Fiji: an opensource platform for biological-image analysis. Nat Methods 9:676-682. CrossRef Medline

Schnaar RL, Gerardy-Schahn R, Hildebrandt H (2014) Sialic acids in the brain: gangliosides and polysialic acid in nervous system development, stability, disease, and regeneration. Physiol Rev 94:461-518. CrossRef Medline

Schwalbe RA, Corey MJ, Cartwright TA (2008) Novel Kv3 glycoforms differentially expressed in adult mammalian brain contain sialylated N-glycans. Biochem Cell Biol 86:21-30. CrossRef Medline
Scott H, Panin VM (2014) The role of protein N-glycosylation in neural transmission. Glycobiology 24:407-417. CrossRef Medline

Seagard JL, van Brederode JF, Dean C, Hopp FA, Gallenberg LA, Kampine JP (1990) Firing characteristics of single-fiber carotid sinus baroreceptors. Circ Res 66:1499-1509. CrossRef Medline

Sinnarajah S, Suppiramaniam V, Kumar KP, Hall RA, Bahr BA, Vodyanoy V (1999) Heparin modulates the single channel kinetics of reconstituted AMPA receptors from rat brain. Synapse 31:203-209. CrossRef Medline

Stummeyer K, Dickmanns A, Mühlenhoff M, Gerardy-Schahn R, Ficner R (2005) Crystal structure of the polysialic acid-degrading endosialidase of bacteriophage K1F. Nat Struct Mol Biol 12:90-96. CrossRef Medline

Sun MK, Guyenet PG (1987) Arterial baroreceptor and vagal inputs to sympathoexcitatory neurons in rat medulla. Am J Physiol 252:R699-R709. Medline

Suppiramaniam V, Vaithianathan T, Manivannan K, Dhanasekaran M, Parameshwaran K, Bahr BA (2006) Modulatory effects of dextran sulfate and fucoidan on binding and channel properties of AMPA receptors isolated from rat brain. Synapse 60:456-464. CrossRef Medline

Sved AF, Schreihofer AM, Kost CK Jr (1997) Blood pressure regulation in baroreceptor-denervated rats. Clin Exp Pharmacol Physiol 24:77-82. CrossRef Medline

Szele FG, Dowling JJ, Gonzales C, Theveniau M, Rougon G, Chesselet MF (1994) Pattern of expression of highly polysialylated neural cell adhesion molecule in the developing and adult rat striatum. Neuroscience 60:133144. CrossRef Medline

Talman WT, Perrone MH, Reis DJ (1980) Evidence for L-glutamate as the neurotransmitter of baroreceptor afferent nerve fibers. Science 209:813815. CrossRef Medline

Taylor G (1996) Sialidases: structures, biological significance and therapeutic potential. Curr Opin Struct Biol 6:830-837. CrossRef Medline

Theodosis DT, Bonhomme R, Vitiello S, Rougon G, Poulain DA (1999) Cell surface expression of polysialic acid on NCAM is a prerequisite for activity-dependent morphological neuronal and glial plasticity. J Neurosci 19:10228-10236. Medline

Theodosis DT, Poulain DA, Oliet SH (2008) Activity-dependent structural and functional plasticity of astrocyte-neuron interactions. Physiol Rev 88:983-1008. CrossRef Medline

Titz S, Keller BU (1997) Rapidly deactivating AMPA receptors determine excitatory synaptic transmission to interneurons in the nucleus tractus solitarius from rat. J Neurophysiol 78:82-91. Medline

Uryu K, Butler AK, Chesselet MF (1999) Synaptogenesis and ultrastructural localization of the polysialylated neural cell adhesion molecule in the developing striatum. J Comp Neurol 405:216-232. CrossRef Medline

Vaithianathan T, Matthias K, Bahr B, Schachner M, Suppiramaniam V, Dityatev A, Steinhaüser C (2004) Neural cell adhesion molecule-associated polysialic acid potentiates alpha-amino-3-hydroxy-5-methylisoxazole-4-propionic acid receptor currents. J Biol Chem 279:47975-47984. CrossRef Medline

Varbanov H, Dityatev A (2017) Regulation of extrasynaptic signaling by polysialylated NCAM: impact for synaptic plasticity and cognitive functions. Mol Cell Neurosci 81:12-21. CrossRef Medline

Venstrom KA, Reichardt LF (1993) Extracellular matrix: 2. Role of extracellular matrix molecules and their receptors in the nervous system. FASEB J 7:996-1003. Medline

Yang H, Zhang G, Cui J (2015) BK channels: multiple sensors, one activation gate. Front Physiol 6:29. CrossRef Medline

Zhang J, Mifflin SW (1998) Differential roles for NMDA and non-NMDA receptor subtypes in baroreceptor afferent integration in the nucleus of the solitary tract of the rat. J Physiol 511:733-745. CrossRef Medline

Zhao H, Peters JH, Zhu M, Page SJ, Ritter RC, Appleyard SM (2015) Frequency-dependent facilitation of synaptic throughput via postsynaptic NMDA receptors in the nucleus of the solitary tract. J Physiol 593:111125. CrossRef Medline

Zhou Z, Champagnat J, Poon CS (1997) Phasic and long-term depression in brainstem nucleus tractus solitarius neurons: differing roles of AMPA receptor desensitization. J Neurosci 17:5349-5356. Medline

Zoccal DB, Furuya WI, Bassi M, Colombari DS, Colombari E (2014) The nucleus of the solitary tract and the coordination of respiratory and sympathetic activities. Front Physiol 5:238. CrossRef Medline

Zuber C, Lackie PM, Catterall WA, Roth J (1992) Polysialic acid is associated with sodium channels and the neural cell adhesion molecule N-CAM in adult rat brain. J Biol Chem 267:9965-9971. Medline 